\title{
Phenomena of illusory form: can we bridge the gap between levels of explanation?
}

\author{
Lothar Spillmann \\ Institute of Biophysics and Radiation Biology, University of Freiburg, Hansastrasse 9, \\ D-79104 Freiburg, Germany \\ Birgitta Dresp \\ Laboratoire de Psychophysique Sensorielle, CNRS-Université Louis Pasteur, 12 rue Goethe, \\ F-67000 Strasbourg, France \\ Received 1 March 1995, in revised form 26 July 1995
}

\begin{abstract}
The study of illusory brightness and contour phenomena has become an important tool in modern brain research. Gestalt, cognitive, neural, and computational approaches are reviewed and their explanatory powers are discussed in the light of empirical data. Two wellknown phenomena of illusory form are dealt with, the Ehrenstein illusion and the Kanizsa triangle. It is argued that the gap between the different levels of explanation, bottom-up versus top-down, creates scientific barriers which have all too often engendered unnecessary debate about who is right and who is wrong. In this review of the literature we favour an integrative approach to the question of how illusory form is derived from stimulus configurations which provide the visual system with seemingly incomplete information. The processes that can explain the emergence of these phenomena range from local feature detection to global strategies of perceptual organisation. These processes may be similar to those that help us restore partially occluded objects in everyday vision. To understand better the Ehrenstein and Kanizsa illusions, it is proposed that different levels of analysis and explanation are not mutually exclusive, but complementary. Theories of illusory contour and form perception must, therefore, take into account the underlying neurophysiological mechanisms and their possible interactions with cognitive and attentional processes.
\end{abstract}

\section{Introduction}

In 1940, Wolfgang Köhler wrote: "it seems to me, our knowledge both of psychological rules and of the nervous system has just reached the stage at which first bridges can be built from one realm to the other. It will be the psychologist's task to take the first steps in this direction" (page 48). More than fifty years later, psychologists are beginning to respond to this challenge, especially in the field of vision research, where phenomenological, psychophysical, neurophysiological, and computational approaches have contributed to a better understanding of the perceptual world.

The study of visual illusions is particularly rewarding in the sense that it offers a glimpse into the workings of the visual system when the physical stimulus and our perception of it do not match. Once we have understood why we perceive coherent forms in stimulus patterns which are ambiguous or seemingly incomplete, we will have gained basic insight into the processes which govern human visual perception in general. In the case of illusory-contour stimuli, a parallel to partially occluded real objects seems obvious. The mechanisms that help us reconstruct the whole from its pieces may be similar to those that produce brightness enhancement and illusory contours in gaps.

Phenomena of illusory brightness and contour have been known for a long time (Meyer and Petry 1987). In vision research, the tradition dates back to the classical studies of Mach (1865-1868) and Hering (1878), who postulated that neural interactions may account for phenomena of border and area contrast. It was continued later by the Gestalt psychologists, who described in detail the conditions under which illusions occur and how they change when these conditions are modified. Their work 
led to the definition of a set of descriptive perceptual rules (Gestalt laws) which are governed by the principle of good Gestalt ('Prägnanzprinzip'-Wertheimer 1923; Metzger 1953).

With the advent of single-cell recording in the late 1950 s and early 1960 s, psychophysicists began to work out behavioural paradigms which allowed them to relate visual effects, including visual illusions, to neurophysiological data. By then, vision scientists were increasingly pursuing and advocating the idea that perceptual phenomena in humans would be better understood if correlated with single-cell responses in the retina, the lateral geniculate nucleus, and the visual cortex of cat and monkey (eg Baumgartner 1961, 1962, 1964; Jung 1961a, 1961b, 1964; Hubel and Wiesel 1962, 1968). The more recent discovery of cortical cells in area V2 of the monkey, responding to gap stimuli which are known to elicit perception of illusory contours in human observers (von der Heydt et al 1984), poses new challenges to psychophysicists and computational vision scientists alike. Although it is generally agreed that the perception of illusory forms must have a specific biological function (Ullman 1976, 1984; Grossberg and Mingolla 1985; Ramachandran 1985, 1987, 1992; Kellman and Loukides 1987; Shipley and Kellman 1990; Peterhans and von der Heydt 1991; Dresp, submitted), it is still unclear at which level of explanation one can best account for it.

Therefore, bridges have to be built to combine the neurophysiological concepts of illusory-contour processing with the psychophysical findings and existing computational models of illusory brightness and form perception. The appearance of two books on this topic (Kanizsa 1979; Petry and Meyer 1987) and an annotated bibliography listing some 450 entries (Purghé and Coren 1992), suggests that a critical discussion of these issues has become a matter of urgency. The aim of this article is to present the empirical data on illusory contours and to evaluate the hypotheses proposed to explain them. This is done in the hope that from such a discourse the dividing line between neurosensory explanations ('bottom-up') and cognitive interpretations ('top-down') will give way to a synthesis under which the various approaches will complement each other for a better understanding of these fascinating phenomena.

\section{Illusory contours, surfaces, brightness, and colour in Ehrenstein and Kanizsa figures}

Brightness enhancement and illusory contours were first reported by Schumann (1900) for a pattern consisting of black semicircles opposing each other across a gap. In the empty region between these semicircles, he observed a white rectangle with sharply defined contours that were physically not present. This rectangular surface appeared lighter than the background surrounding the pattern. Schumann considered this phenomenon a special example of simultaneous contrast.

A very different figure producing a similar brightness effect was introduced by Ehrenstein (1941, 1954). He demonstrated that uniform brightness changes may occur even when large contrasting areas are absent. In figure 1, a 'whiter-than-white' disc is seen in the central gap between black converging lines presented on a white background, and a 'blacker-than-black' disc between similarly arranged white lines presented on a black background. This is the well-known Ehrenstein illusion. It is readily seen foveally and out to about $10 \mathrm{deg}$ eccentricity (Spillmann et al 1976). The illusory discs stand out relative to the figure and are delineated by a circular illusory contour. When a ring is superimposed onto this contour, so as to connect the inner tips of the inducing lines, the brightness illusion disappears (Ehrenstein 1941, 1954). Brightness enhancement is also reduced or absent when the radial lines are so wide or so many in number as to supplant the illusory contour completely. Ring enclosures smaller or larger than the central gap have less or no effect on the strength of the illusion (Spillmann 1977). 
A stimulus configuration which produces brightness enhancement similar to Schumann's was devised by Kanizsa $(1955,1974)$. It is made of three black discs with cutouts ('pacmen') aligned at the corners of a virtual triangle (figure 2a). In this configuration, a bright triangular surface can be seen, although there is no difference in luminance between figure and ground. A square version of the same figure

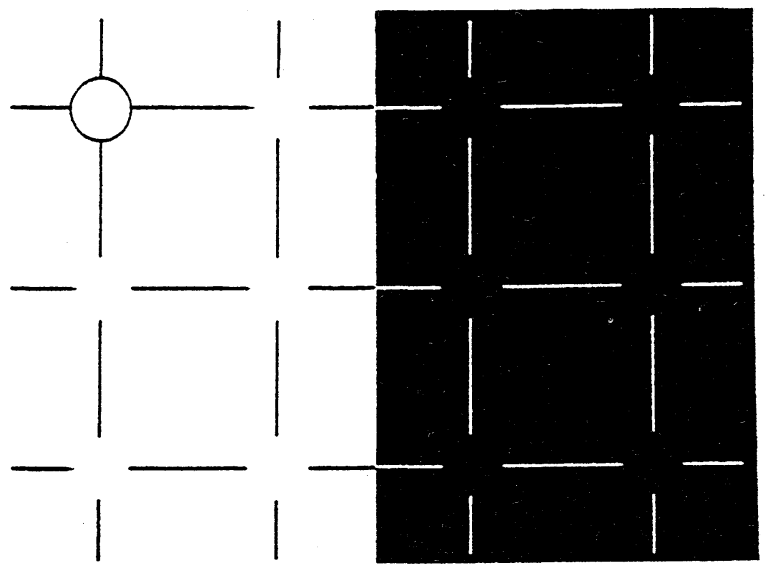

Figure 1. Ehrenstein's brightness illusion. Light and dark illusory patches surrounded by a sharp subjective contour are seen in the central gaps formed by radial lines. The illusion disappears when enclosed by a circular real contour (after Ehrenstein 1941).

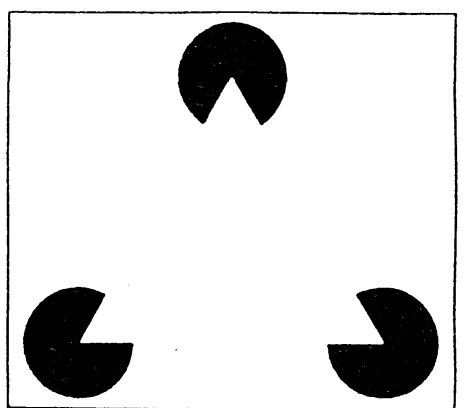

(a)

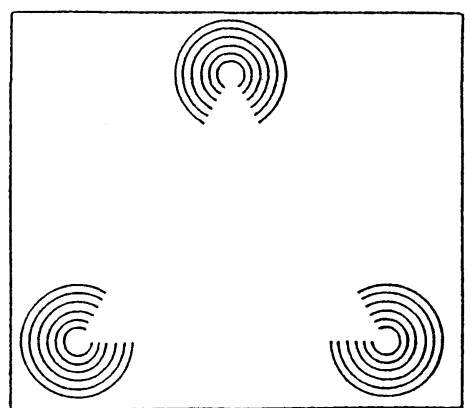

(b)
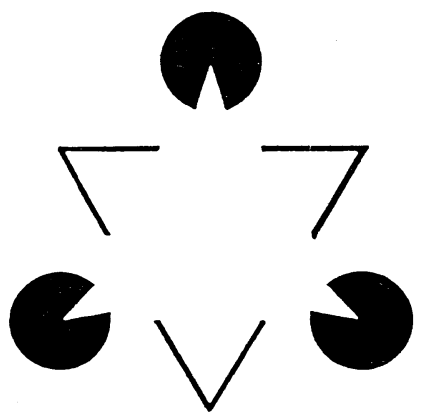

(d) (c)
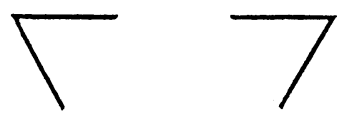

Figure 2. (a) Kanizsa's triangle induced by sectored black discs. The illusory triangle is delineated by a sharp subjective contour bounding a region of enhanced brightness (from Kanizsa 1955). (b) An illusory triangle induced by sectored concentric circles (from Varin 1971). (c) An illusory triangle induced only by dots and broken lines (from Gregory 1972). (d) A modified Kanizsa triangle with curved, instead of straight, sides (from Gregory 1972). 
is obtained by an appropriate arrangement of four discs with rectangular cutouts (Varin 1971). As in the Ehrenstein figure, a sharp illusory border, or edge, is perceived, bounding the area of brightness enhancement.

Although the Kanizsa triangle is usually presented with high-contrast black or white sectored discs, it can also be induced by appropriately sectored concentric circles (figure $2 \mathrm{~b}$ ), or by a sequence of short parallel lines abutting the incomplete triangle at right angles (Varin 1971; Frisby and Clatworthy 1975; Frisby 1979). However, whereas in the first case (solid inducers) the illusory contours extend collinearly with the edges formed by the sectored discs, in the latter cases they extend orthogonally to the tips of the inducing lines. For later discussion (see pages 18, 23), two important variants of the Kanizsa triangle from Gregory (1972) are included here. In figure 2c, three dots have been added to the open sides of a 'broken' triangle to demonstrate illusory contours in the absence of solid edges or concentric rings. Note that neither the dots nor the lines alone will elicit an illusion. In figure $2 \mathrm{~d}$, the blank sectors have been narrowed so that corresponding inducing edges are no longer aligned. As a consequence, curved contours are perceived which deviate from the extrapolated, straight orientations of the sector angles (see also Kanizsa 1955, 1974).

Brightness induction across luminance edges, on one hand, and by ends of lines, on the other, are usually regarded as two different phenomena, referred to as area contrast and line-end contrast (Frisby and Clatworthy 1975; Day and Jory 1978). The latter type of contrast refers to the small 'lightness buttons', emanating from the ends of lines (Prandtl 1927; Kennedy 1978b, 1979). Both kinds of contrast engender similar effects and may coexist in the same figure. A number of authors (Frisby and Clatworthy 1975; Halpern 1981; Petry et al 1983; Hershberger and Stallard 1984) have studied various examples of collinearly and orthogonally induced illusory contours and found them to be about equally strong. Generally, the strength of induction depends on contrast variability, eg the number, width, spacing, and angle of the inducers (Lesher and Mingolla 1993).

\subsection{The separability of illusory brightness and illusory contour}

In their search for the determinants of illusory form, researchers have looked for causal links between induced brightness and illusory contours (eg Day and Jory 1978, 1980; Kanizsa 1979; Parks 1979; Prazdny 1983; Watanabe and Oyama 1988). However, conclusive evidence that one of the two is a consequence of the other has not been found. Although brightness enhancement and illusory contours usually occur together, there are examples where they do not. Under certain conditions, illusory contours may emerge without enhanced brightness and, conversely, brightness enhancement may exist in the absence of illusory borders. These two characteristics of illusory form may thus be independent of each other and should be evaluated separately (Jory and Day 1979; Halpern 1981; Ware 1981; Petry et al 1983; Dresp 1992; Dresp et al, in press).

Figure 3 shows three examples of illusory contours without illusory brightness: in figure 3a a modified Ehrenstein figure (Parks 1980b); in figure 3b a pair of abutting line gratings shifted in phase (Kanizsa 1974, 1976; see also Sambin 1975, 1977; Richardson and Wuillemin 1981; Prazdny 1983; Kennedy 1988; Soriano et al, in press); and in figure $3 \mathrm{c}$ along the corners of grating stimuli bordering each other at an angle (Day 1987; see also Kennedy and Chattaway 1975). For comparison, figure 4 (upper left) shows a Koffka cross (Koffka 1935) exhibiting brightness enhancement in the central area, but having little, if any, illusory contour. Note how adding small dots at different positions within the Koffka figure sharpens up the illusory contour and changes the perceived shape of the illusion from circle to square and diamond (Landauer 1978; Day 1986, 1987). 


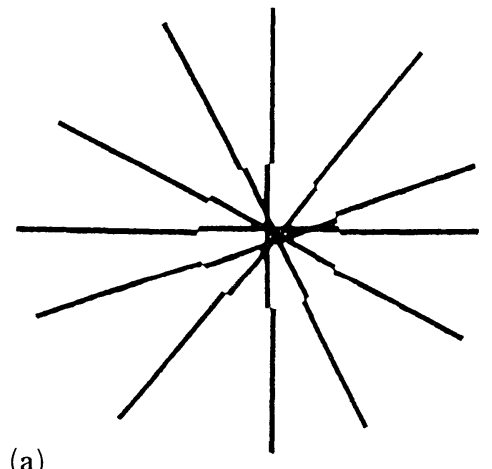

(a)

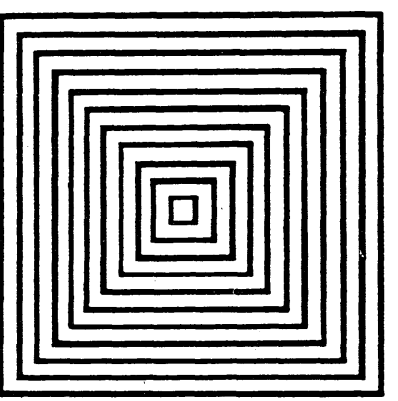

(c)

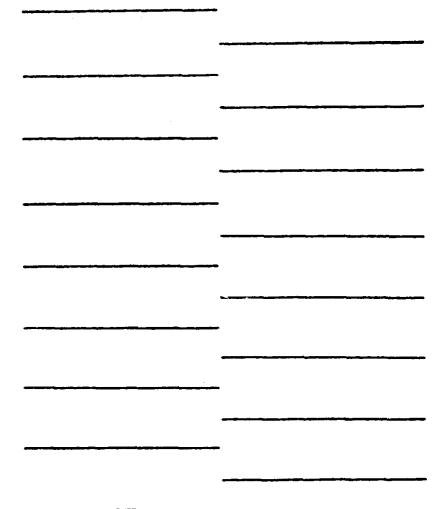

(b)

Figure 3. (a) An illusory contour, but no brightness enhancement, is seen in this modified Ehrenstein figure with offset lines inserted into the central gap (from Parks 1980b). (b) A sharp illusory line or edge separates the two phase-shifted line gratings (from Kanizsa 1976). (c) Illusory contours running along the corners of the grating lines (from Day 1987).

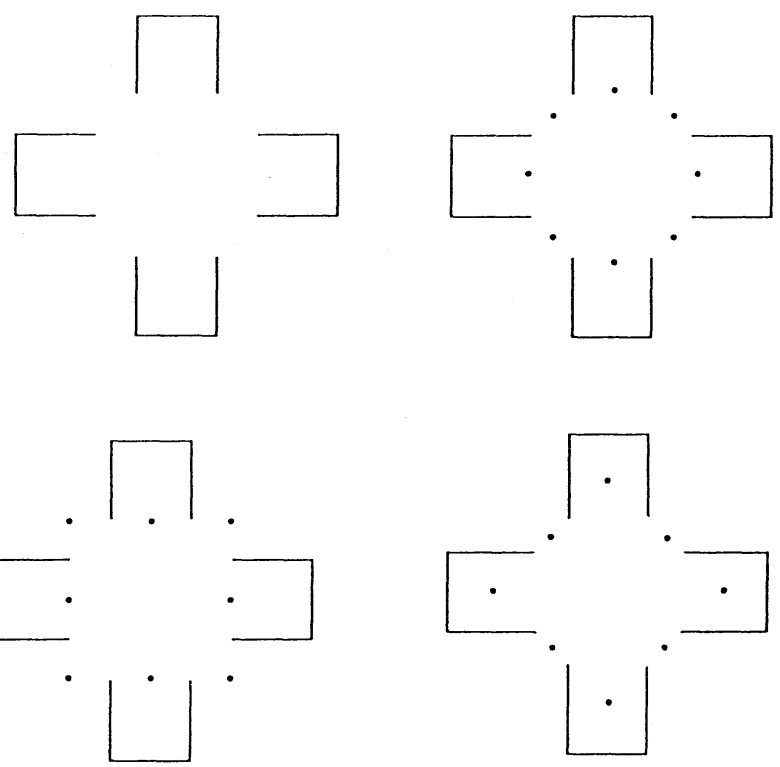

Figure 4. The Koffka cross. In the upper left figure, brightness enhancement is perceived with little, if any, illusory border. When small dots are added around the region of enhanced brightness, a sharply delineated circle, square, or diamond is seen (from Day and Jory 1980). 
To account for the origin of illusory form, Day and Jory $(1978,1980)$ and Jory and Day (1979) proposed a two-stage contrast model. At the first stage, brightness enhancement is generated by three interrelated perceptual processes: area contrast, assimilation, and dissimilation. The extent to which each of these processes will contribute to the strength of a given illusion depends on the geometric configuration of the inducing stimulus (see also Kellman and Shipley 1991). According to Day and Jory, area contrast would account best for brightness enhancement in the standard Kanizsa triangle, whereas a combination of assimilation and dissimilation would explain the enhanced brightness in the Ehrenstein illusion. By assimilation, the authors mean the reduction of brightness in the interspaces between lines lying side by side; by dissimilation, the increase of brightness in the central region enclosed between lines lying end to end (line-end contrast).

At a second stage, illusory contours may be generated between partially defined physical borders which confine the spread of brightness to a region compatible with the inducing stimuli. These physical borders may be small boundary markers such as regularly arranged line ends, dots, or edges defining a certain area within the stimulus configuration (Gregory 1972; Day and Jory 1980). The illusory contour forms by connecting these boundary markers, either collinearly (as in the Kanizsa triangle) or at right angles (as in the Ehrenstein figure), thereby enclosing the area of brightness enhancement with a smooth border (see also Frisby and Clatworthy 1975; Kennedy 1976a, 1978b, 1979; Day and Jory 1980; Sambin 1987). As with the superimposed ring mentioned earlier, short orthogonal stops attached to the ends of lines weaken or eliminate the illusory effect (Spillmann 1975; Sambin 1977; Day and Jory 1978).

Kennedy (1976a, 1988) and Petry et al (1983) have shown that the illusory contour produced by line-end contrast depends not only on the orientation of the inducing lines (slanted and tangential lines fail to elicit an illusion), but also on the shape of the line tip. In Kennedy's studies, thin lines and squared-off terminations produced the strongest illusory contour. Rounded tips produced an illusory contour that was weaker, and tapered and bevelled lines elicited no illusory contour at all, but a diffuse glow. Diffuse, fuzzy contours surrounding an area of brightness enhancement have also been shown with other stimuli where the tips of the inducing elements were orientationally ambiguous (Kennedy 1975, 1976b, 1978a, 1981; Kennedy and Ware 1978; Richardson 1979; Parks 1982; Fraser 1983; Masini and Perussia 1983).

\subsection{The effect of illusory surface}

When the Ehrenstein figure is presented on various textured backgrounds, there is neither brightness enhancement, nor illusory contour (Spillmann 1975; Spillmann et al 1976; Rock and Anson 1979; Ramachandran 1987). However, there may be a change of surface quality. In figure 5, the Ehrenstein figure has been superimposed onto a random-dot field. As a consequence, some observers report that the dots inside the illusory area appear to change in grain (they look less dense) and to become organised into clusters or blobs (Spillmann 1977). This is similar to the rarefaction phenomena reported by Kennedy and Lee (1976) and Bressan (1987). Others see only an illusory surface, but no textural change. Still others say that the dotted area appears to bulge forward through the gap, a sort of stereo capture (eg Ramachandran and Cavanagh 1985; Ramachandran 1986). Analogously, the illusory clusters may also be dragged out of the central gap by moving either the Ehrenstein figure or the background, ie motion capture (Spillmann and Redies 1981; Ramachandran and Inada 1984).

Depth and motion are powerful determinants of illusory surface and thereby contribute to figure-ground segregation. For example, in a sparse Julesz-type stereogram, regions with different stereo-depths are perceived as stacked surfaces delineated 
by smooth edges (Julesz 1971). Similarly, a designated random-dot region moving within a larger pattern of random dots is seen as a moving surface enclosed by sharp illusory edges (van Doorn and Koenderink 1982). These surfaces and edges are generated entirely by depth and motion cues; as soon as binocular fusion is lost or movement stops, the edge disappears.

In the Ehrenstein and Kanizsa figures, surface properties such as depth, transparency, and opacity have recently been studied in relation to brightness and colour spreading on areas surrounded by illusory contours (eg de Weert and van Kruysbergen 1987; Nakayama et al 1990; Watanabe and Cavanagh 1991, 1993; Bressan 1993). The perception of stereo depth plays an important role in image segmentation. It enables us to attribute an illusory surface to the foreground or the background of a visual scene; in the first case, the illusion is strengthened, in the second it is weakened. However, although these surface properties are highly correlated, their interrelationship is far from being understood.

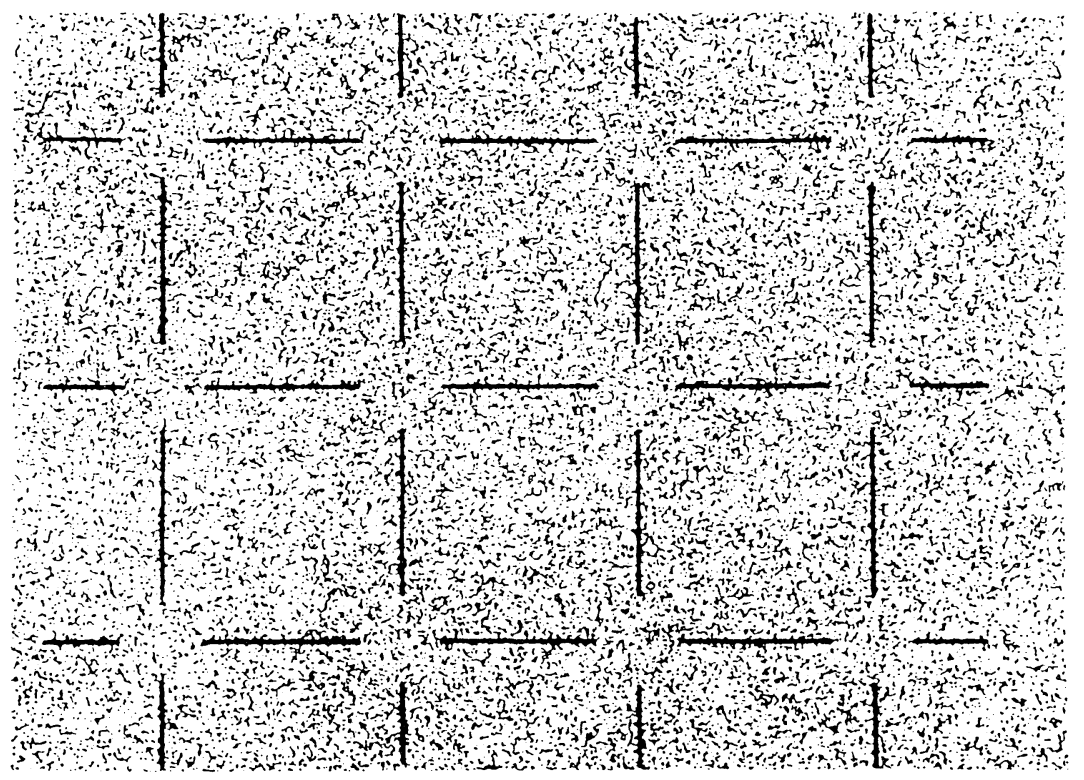

Figure 5. When the Ehrenstein figure is placed on a random-dot background, the dots inside the illusory area appear to be organised in clusters (from Spillmann 1977).

\subsection{The biological significance of illusory contours}

The perception of illusory contours and surfaces may be biologically significant in a world where natural forms are frequently obscured and fragmented by occluding objects or by camouflage. Ramachandran (1985, 1987) noted that many species possess as a natural protection against predators coats with stripes or splotches that break the outlines of the body shape (ie as long as the animal is stationary). Thus, visual mechanisms that allow the visual recovery of camouflaged outlines are likely to have evolved. It is reasonable to assume that the perception of illusory contours is generated by mechanisms that are similar to those that are used by visual systems to counteract camouflage. Everyday life of both man and animal is full of situations where information on contour and shape is partially lacking. To restore a complete image from a fragmented visual world, perceptual systems must use processes which ensure the integration of the fragments into a coherent and nonambiguous representation of the occluded stimulus. This task likely involves the perception of illusory 
contours to close gaps in the stimulus, and of illusory brightness to sketch out a camouflaged surface (Frisby and Clatworthy 1975).

Knowing by which mechanisms such an integration is accomplished is critical to our understanding of illusory form. Although global cognitive processes may play a determinant role in perceptual completion (eg Shipley and Kellman 1990; Sekuler and Palmer 1992), there are many examples where problems of occlusion are solved without knowledge of what objects are hidden. Enns and Rensink's (1993) demonstration that rapid perceptual completion is possible in complex geometrical shapes strongly suggests the existence of mechanisms which achieve completion independently from object recognition. Similarly, Ullman (1976), Marr (1976, 1982), and Zucker and Cavanagh (1985) suggest that there are filling-in mechanisms in early vision which rely essentially on the processing of local cues and operate before an interpretation of the image takes place. In a natural environment, local cues for occlusion are readily available at line ends and other sharp discontinuities, eg T-junctions formed by branches (Kennedy 1988; Shipley and Kellman 1990, 1992a; Kellman and Shipley 1991; Peterhans and von der Heydt 1991; Enns and Rensink 1994; Dresp, submitted).

In view of its possible biological significance, it is important to address the question of the phylogenetic and ontogenetic aspects of illusory form perception. Only a few researchers have attempted to shed light on this issue. Experiments involving the preferential-looking procedure have shown that 3-7-month-old children can already discriminate between illusory arrays of the Kanizsa type and nonillusory stimuli containing the same, but differently oriented, figure elements (Bertenthal et al 1980; Ghim 1990). Illusory-contour discrimination at a very early age has also been reported for the abutting-grating illusion (Rieth and Sireteanu 1993). On the other hand, Soubitez (1982), using a Donald Duck figure with a real and an illusory eye, found that children can perceive the Ehrenstein illusion only after age 4 to 5 years. Interestingly, this is the same age range in which children can perceptually complete and correctly identify images in fragmented stimulus patterns (Gollin 1960; Abravanel 1982).

Data have also become available on the perception of illusory form in animals. Experiments with different discrimination paradigms suggest that chicks (Zanforlin 1981) and cats can 'see' illusory contours (Bravo et al 1988; Corbetta et al 1989; de Weerd et al 1990). In further studies it is claimed that even bees and dragonflies are able to 'detect' illusory contours (Hateren et al 1990; Horridge et al 1992). Indeed, neurons in the optic lobe of the dragonfly have been found to respond to a parallel shift of two abutting gratings as if to the motion of a real edge.

However, these behavioural and neurophysiological results must be interpreted very carefully. One might ask, what were the criteria used for discriminating an experimental figure from a nonillusory control figure? Was the discrimination based on the perceptual presence or absence of an illusory contour, or was it simply determined by misalignment of the inducers, configurational asymmetry, or differences in mean contrast due to a sampling artefact by the insect eye? Obviously, further research is needed to provide conclusive evidence on perception of illusory brightness and contour in children and animals.

\subsection{Earlier explanations that do not work}

The question whether the perception of illusory form may result from an adapting biological mechanism has arisen only recently. In his pioneering paper, Ehrenstein (1941) proposed an explanation of illusory forms on the basis of eye movements. He assumed that in the interspaces between the inducing lines of the Ehrenstein figure, the black of the lines and the white of the background would mix (ie assimilate) to yield a 
light grey. However, the central region of the figure would be relatively spared and would thus appear brighter than the immediately adjacent regions of the background. The assumption that such an assimilation would be mediated by small eye movements is, in fact, not tenable. Spillmann et al (1976) and Reynolds (1981) found that the Ehrenstein illusion is perceived with exposure durations too short to allow for eye movements $(30-100 \mathrm{~ms})$; and that it is present in stabilised vision as well as in the afterimage following exposure of the pattern by a flash. Eye movements may therefore be ruled out as an explanation, although they may help to sustain the effect. Similar results have been obtained in the Kanizsa triangle (Ronchi and Mori 1959; Pastore 1971; Gregory 1972; Kennedy and Chattaway 1975).

Another explanation that may be excluded is a model based on the receptive-field organisation of the retina, as in the example of the Hermann grid illusion. Whereas the bright and dark spots at the intersections of a Hermann grid can be largely understood on the basis of the centre-surround antagonism of retinal receptive fields (for a review see Spillmann 1994), the same simple mechanism does not hold as an explanation for the large (0.5-1 deg), uniform brightness enhancement in the Kanizsa and Ehrenstein figures (Spillmann et al 1976; Shapley and Gordon 1987). More complex assumptions are needed.

In view of the great variety of figures that give rise to the perception of illusory form (see Kanizsa 1979), a straightforward and general explanation of these phenomena might thus be hard to find. Furthermore, the methodological and conceptual differences between the various approaches make a clear and distinctive categorisation of the various phenomena difficult. This difficulty is reflected in the multitude of names that have been used by different authors to refer to illusory contours: 'apparent edges' (Schumann 1900), 'quasi-perceptive contours' (Kanizsa 1955), 'virtual contours' (Mori 1959; Goldstein and Weintraub 1972), 'incomplete borders' (Mori and Ronchi 1960), 'anomalous contours' (Lawson and Gulick 1967; Minguzzi 1982, 1984; Sambin 1987; Peterhans and von der Heydt 1991), 'cognitive contours' (Gregory 1972), 'subjective contours' (Coren 1972; Kanizsa 1976), 'contours without gradients' (Kanizsa 1974), 'illusory contours' (Petry and Meyer 1987), and 'contours bridging gaps' (Peterhans and von der Heydt 1989). Some of these terms date back to the earliest attempts to explain illusory form. Current theories are still influenced by these terminological differences.

In the following section we discuss the principal theoretical and empirical approaches to illusory contours and surface brightness as the two constituting attributes of illusory form.

\section{Gestalt and cognitive approaches: descriptions, not explanations}

The principles governing perceptual organisation in real and illusory visual form were established by the Gestalt psychologists (Rubin 1921; Wertheimer 1923; Galli and Hochheimer 1934; Koffka 1935; Köhler 1940; Metzger 1953; Ehrenstein 1954; Kanizsa 1979). The Gestalt approach is based on the phenomenological exploration, description, and identification of the perceived attributes of the stimulus. At this first level of analysis, the issue is not to explain a visual phenomenon, but to gain insight into the structural rules that govern its emergence (Kanizsa and Caramelli 1988; Legrenzi 1988). Whenever we attempt to explain human perception, we do so on the basis of phenomenological attributes. Unless these have been systematically studied and described, our explanations must be necessarily incomplete. The Gestaltists proposed that the transformation from a physical stimulus to an illusory percept is governed by the same organisational rules as the emergence of real form. This approach from stimulus to percept at increasingly higher levels of structural organisation has been called 'bottom - up'. 


\subsection{The concept of Gestalt completion}

The notion of Gestalt completion for explaining illusory surfaces was introduced by Kanizsa $(1955,1974,1976,1979)$ to account for brightness enhancement in both the Ehrenstein illusion and the Kanizsa triangle. It implies that the observer perceives the illusory surface because this is the simplest and most economic way in which the (apparently incomplete) stimulus configuration can be seen as a 'whole'. The completion process closes gaps by forming transitions, or connections, between parts of a configuration. Completion in the Gestalt approach occurs because of an inherent tendency towards a good Gestalt, ie Prägnanz. (Kanizsa later changed his view; see Petry and Meyer 1987, page 49.) Since the completion process connects parts of a configuration across an area which provides no structural input of its own, illusory forms have been referred to as amodal perceptions (Day and Kasperczyk 1983a).

Several authors (eg Kellman and Loukides 1987; Sambin 1987; Shipley and Kellman 1992a, 1992b) still use the term amodal completion to explain how the formation of perceptual units is achieved by a cognitive system. However, its value as an explanation for illusory contours and surfaces appears to be limited (see, for example, Purghé 1988, 1991). This can be demonstrated in the Ehrenstein illusion, which persists to a considerable extent even when the inducing lines do not converge to a common centre, when they are laterally displaced, rotated, curved, or fragmented into dashes or strings of dots (Spillmann 1975; Kennedy 1976b; Minguzzi 1982). Under these conditions, cues for closure are minimal, or absent, and yet brightness enhancement is seen.

Figure 6a shows an example where an illusory square is induced by (open-ended) lines of different orientations. Although these lines do not continue on the other side, the bright area is quite pronounced. Similarly, an illusory triangle, albeit weak, will be seen when the sharp-edged, solid inducers in the Kanizsa figure are replaced by equally shaped clusters of loosely spaced dots (Kanizsa 1974, 1976; Frisby and Clatworthy 1975; Kennedy and Ware 1978). These findings pose a challenge to the Gestalt explanations of brightness enhancement and illusory form by good continuation and completion (cf Gillam 1987; Field et al 1993). On the other hand, in the standard Kanizsa figure a rotation of the inducers by only a few degrees will eliminate the contours and only bright, fan-shaped flares extending from the sectors will remain (Mori and Ronchi 1960).

In the late $1960 \mathrm{~s}$, psychologists began to think of alternatives to Gestalt explanations of form perception. With the advent of cognitivism, perceptual theory became

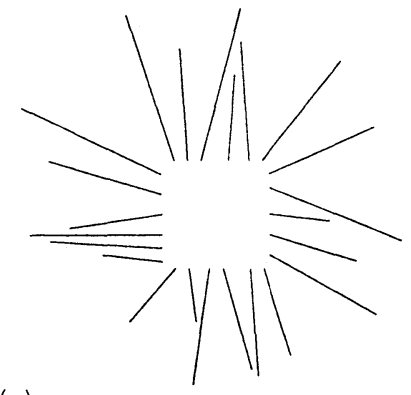

(a)

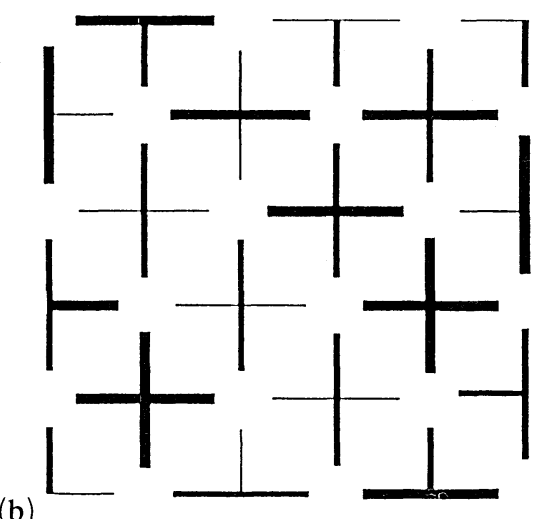

(b)

Figure 6. (a) An illusory surface induced by jumbled, noncollinear line segments (from Albert and Hoffman 1995). (b) Brightness enhancement and illusory contours persist in spite of different stroke widths of the inducing lines. Note the illusory 'streets' along the diagonals. 
concerned with what is going on in 'the mind', or 'the brain'. With Gregory's fascinating books Eye and Brain (1966) and The Intelligent Eye (1970), the problemsolving approach to perception and visual illusions was born.

\subsection{Illusory contours as intelligent solutions to perceptual problems}

The concept of perceptual strategies is implicit to a whole class of hypotheses that emphasise the role of cognitive factors as the determinants of illusory figures and are, therefore, called top-down. Within this framework illusions are not solely regarded as the results of the sensory processing of the physical stimulus, but rather as constructs that emerge on the basis of what the observer implicitly knows about objects and their spatial relationships in the world. The cognitive approach to the perception of illusory form was introduced by Gregory $(1972,1973,1974)$ and later adopted by other authors (Rock and Anson 1979; Rock 1987; Parks 1987, 1989). It goes beyond the sensory stimulus by invoking higher-order templates for its figural interpretation. According to this theory, our perception is guided by problem-solving strategies such as high-probability inferences, object hypotheses, and perceptual postulates by which we seek to resolve ambiguities in the stimulus in the most plausible manner (Gregory 1980, 1986, 1992). In the case of illusory surfaces, a local absence of physical stimulation (ie a gap) would be interpreted in terms of an object partially overlying the stimulus (ie the inducing elements). In this respect, the perception of illusory brightness and contours is seen as the result of an active attempt by the brain to organise an incomplete stimulus so as best to account for its 'missing' parts.

Applied to the particular example of the Kanizsa triangle, the most plausible perceptual postulate would be that of an opaque triangle partly occluding three discs. In this way, the figural integrity of the stimulus is restored and a coherent representation of form emerges. Within such a hypothesis, figure-ground segregation is, paradoxically, considered the cause of the illusion rather than a consequence (Parks 1986, 1989). The question of how figure-ground segregation can take place before perception of illusory contour and brightness has never been explicitly raised within the problem-solving approach. In fact, in recent approaches it is suggested that the illusory contours have to be generated before any figure-ground organisation, or depth stratification, can be achieved (eg Ullman 1976; Day and Jory 1980; Grossberg 1994).

An argument in favour of the 'inference-of-occlusion' hypothesis can be found when the tips of the lines in the Ehrenstein figure do not lie on a circle or square (Gregory 1987; Bruno and Bertamini 1990), but rather terminate at different irregular locations relative to the centre. Under these conditions, the illusory surface will appear to become distorted and will ultimately disappear. This observation has been interpreted as support for a cognitive explanation of the Ehrenstein illusion (Gregory 1987). On the other hand, low-level mechanisms may account for the failure of an occluding surface to arise in perception when the shape and location of the inducers suggest a highly unlikely object (Paradiso et al 1989).

As an alternative to Gregory's (1972) cognitive inferences, Nakayama and Shimojo (1992) therefore suggest that illusory-form perception may be explained by bottom-up neural mechanisms and inference-like processes in early vision. These low-level perceptual inferences are assumed to be based on image sampling during locomotion and previous associative learning. Whenever the observer is presented with image data that allow for more than one surface interpretation, the visual system chooses the percept that is most appropriate to a generic (as opposed to an accidental) viewpoint, ie the surface with the highest probability (Albert and Hoffman 1995). A testing of cognitive hypotheses and perceptual postulates is not required. Nakayama and 
Shimojo (1992) do not deal with the specific neuronal aspects that might underlie illusory-form perception. Rather, they provide a plausible way in which perceptual inferences may be learned by experience and thus bridge the gap between higher-level and lower-level explanations of the formation of illusory contours and surfaces (Nakayama et al 1995).

In both these approaches, the perception of depth is basic to the strength of the illusion. When stereoscopic depth information compatible with the monocular occlusion cues is introduced, the Kanizsa triangle is enhanced (Gregory 1972; Bloomfield 1973; Lawson et al 1974; Whitmore et al 1976); conversely, when conflicting stereo information is added, it is degraded or eliminated. In this case, the illusory triangle is sometimes seen as if it were bending forward from behind the gaps, yielding an occluding surface that appears to lie in the front plane (Gregory and Harris 1974).

A similar degradation occurs for neon colour spreading (Varin 1971; van Tuijl 1975; van Tuijl and de Weert 1979; Ware 1980; Redies and Spillmann 1981; Redies et al 1984). When a coloured cross is inserted into the central gap of the Ehrenstein figure so as to connect the inner end points of the opposing black lines, the illusory disc will assume a transparent glow in the colour of the cross (eg van Tuijl 1975). It also appears to float above the stimulus. This percept has been attributed to a perceptual scissioning of the assimilative background colour into the plane of the disc (Bressan 1993; see also Gerbino and Kanizsa 1987). In this way the underlying black and coloured lines would acquire a phenomenal unity. Transparency of the neon colour is, in fact, critical. Nakayama et al (1990) found that when the coloured cross of a stereoscopically presented Ehrenstein figure appears to lie in front of the inducers, the illusory surface looks transparent (film-like), clearly delineated and vigorous neon spreading is seen (see also Meyer and Dougherty 1987). In contrast, when the inner cross is perceived as lying behind the inducers, the illusory area looks opaque and there is little, if any, colour spreading (see also Nakayama and Shimojo 1990). Transparency is not restricted to colour. Texture inserted in the gap will also appear transparent (Watanabe and Cavanagh 1991).

Although stereo depth and monocular depth cues act synergistically, the relationship between them is still not fully understood. Each of them can create illusory contours and surfaces independently of the other. Frisby and Clatworthy (1975) therefore suggested that illusory figures produced by lateral disparity may be different from monocularly induced apparent depth. The finding by Mustillo and Fox (1986) that sharp illusory contours can be observed in Kanizsa-type random-dot stereograms which are completely devoid of monocular brightness cues makes the same point (see also Shipley 1965; Julesz and Frisby 1975; Prazdny 1985). These problems are currently being investigated by psychophysicists and computational vision scientists.

\subsection{The role of attentional factors}

The idea that illusory forms are a consequence of a conscious and attention-guided exploration of the stimulus pattern has been referred to as the 'organisational-andattentional-effects' hypothesis (Halpern 1981). It has been advocated by a number of authors in various studies (eg Pritchard and Warm 1983; Bradley and Mates 1985; Bradley 1987; Coren et al 1987). For example, to demonstrate the importance of conscious processes to the perception of illusory figures, Bradley and Mates (1985) tested observers who were unfamiliar with phenomena of illusory form. One group of subjects was merely asked to describe what they saw, another group, whether they perceived brightness enhancement and illusory contours in a Kanizsa triangle. In the latter case, all subjects confirmed having seen the illusion, whereas in the first group, only a few observers spontaneously mentioned the illusory triangle (see also Wallach 
and Slaughter 1988). The authors therefore concluded that the perception of illusory figures is mediated by conscious processes and attention. Similar results were obtained by Pritchard and Warm (1983) and Coren et al (1987). They found that the perception of illusory contours depends on the information about the stimuli given to the observers, as well as on the experimental task, and that it is subject to interindividual and intraindividual differences. Consequently, the perception of illusory form might be influenced by contextual and attentional processes, sometimes referred to as 'cognitive set' (Coren et al 1987).

What do these conclusions tell us? A simple demonstration may suffice to illustrate how attentional factors can contribute to the formation of illusory form. If we go back to figure 4 and ask naive observers to report whether they see a bright circle within the centre of the Koffka cross, they will answer, "yes, of course". On the other hand, if we ask other observers whether they see a bright square, or a diamond, they might also say "yes, of course". It is well known that expectations and prior information (whether right or wrong) influence our way of perceiving the world. However, this does not explain why we see illusory figures, nor by which mechanisms these perceptions are generated. Perceptual organisation in the Ehrenstein and Kanizsa illusion may be modified through attention, yet there is ample evidence that these phenomena normally arise without the help of higher processes. This is demonstrated by the fact that illusory figures 'pop out' at unsuspecting observers, indicating that contour and brightness information are processed preattentively (Gurnsey et al 1992). Nakayama and Shimojo's (1992) theory of preattentive, inference-like processes at a relatively low level is very much in this vein.

\subsection{Do implicit depth cues explain why we perceive illusory figures?}

Somewhere in between Kanizsa's (1955) Gestalt and Gregory's (1972) cognitive approach may be placed the observation by Coren (1972) that illusory figures may be seen 'from above', as if they were lying on an elevated plane partly covering the physical stimulus underneath. The perception of apparent depth in illusory figures prompted him to suggest implicit monocular depth as an explanation of illusory form. This approach has been referred to as the 'cues-to-depth' hypothesis (Halpern 1981). The depth cues would be responsible for both figure brightness and subjective contours (Coren and Theodor 1975; Parks 1979, 1980a). Brightness or darkness enhancement is, in this theory, interpreted as the consequence of perceived interposition. Since an illusory figure is seen as lying in between the plane of the background and the observer, it must be brighter (or darker) than the background. Surface enhancement is considered a necessary step towards a coherently organised depth percept. The illusory contour would then arise from depth stratification and figureground segregation.

Some findings seem to fit in with this 'cues-to-depth' hypothesis. First, a small disc superimposed onto the illusory area looks slightly smaller than on the adjacent background. This would be expected if (inappropriate) size-constancy scaling took place (Coren 1972). Second, the difference in perceived depth between the illusory figure and its background is greater than for nonillusory control figures (Harris and Gregory 1973; Coren and Porac 1983). Third, induced depth stratification by stereopsis can, as already mentioned, play a major role in the formation and suppression of illusory brightness and subjective contours.

However, there are other examples that cannot easily be reconciled with the cuesto-depth hypothesis. Figure $6 \mathrm{~b}$ shows a modified Ehrenstein pattern where the inducing lines have different stroke width. Yet, the bright illusory blobs are very prominent and, in addition, appear to be connected by a lattice of pale diagonal 'streets' (Spillmann 1975). Similarly, when the inducing lines of the Ehrenstein figure are 
differently coloured or have different contrast, brightness enhancement and illusory contours continue to be seen. In each of these cases it is difficult, or even impossible, to conceive collinear lines as belonging to the same single stimulus upon which an object has been superimposed. Interposition cues in the sense of disappearance and reemergence of a partially occluded line might therefore not be available in these configurations (see also figure $6 \mathrm{a}$ ).

Similar comments have been made by Kennedy $(1975,1976 a, 1978 a, 1981)$ on variations of the Ehrenstein figure, and by Day and Kasperczyk (1983a, 1983b) on observations in modified Kanizsa patterns. Their observations show that illusory contours and surfaces can be seen in figures where the inducers and the brightnessenhanced area are perceived as coplanar (Ware and Kennedy 1977, 1978). These results strongly suggest that illusory form and apparent depth are independent phenomena. The authors conclude that depth stratification from monocular interposition cues may contribute to the perceived strength of a given illusion; however, the idea that it is a causal factor is not tenable. Interposition may arise either subsequent to, or concomitant with, illusory form (cf Bradley and Dumais 1975; Rock and Anson 1979), but it has not been shown to be causal to these phenomena.

This problem is easily overcome in recent computational theories of illusory contour perception in which the role of local cues to occlusion is emphasised. For example, Heitger and von der Heydt (1993) do not require that the resulting percept must appear in depth, nor that the local occlusion cues be consistent with a single, occluded object. Thus, the features occluded by a figure with illusory contours need not have the same attributes (width, colour, contrast); what matters is only the local termination of a given inducing element. For perceptual grouping, a minimum of two inducers (edges or line ends) is sufficient. This may not be quite enough for eliciting perception of an occluding illusory surface. On the basis of their concept of genericity, Albert and Hoffman (1995) add that a tangent discontinuity (an abrupt change in the orientation of the inducing contour) is necessary to see occlusion. For example, if the pacmen eliciting brightness enhancement in the Kanizsa square have lips that are not sharp but rounded, no occluding surface will occur.

\subsection{Toward new levels of analysis and explanation}

A review of the various earlier studies of illusory figures suggests that these phenomena have multiple determinants (see also Halpern 1981, 1987; Halpern and Salzman 1983; Halpern et al 1983). Neither the Gestalt nor the cognitive approach were successful in providing satisfactory explanations. Although it is true that general rules, or laws, of perceptual organisation govern the structure of our visual representations and that probable objects are more readily perceived than improbable objects, it must be emphasised that all this applies to both real and illusory forms.

The key issue to be addressed is not the boundary conditions under which illusory brightness and contours occur, but the specific processes by which they are generated. The question then is: are the gaps in the stimulus perceptually completed by neurosensory mechanisms or by inference; and is a stimulus-inherent need for interpretation sufficient to produce perceptual data (ie occlusion) from the absence of sensory signals (ie gaps)? Even if the resulting illusions were 'cognitive fictions' (Gregory 1972, 1992), the fact that we cannot see the Kanizsa figure in the physically correct way (without the bright 'mask' overlying it) testifies to the power of the underlying mechanisms. The truth likely lies in the middle, encompassing both bottom-up and top-down processing.

Recent neurophysiological findings show that cells in the visual cortex respond to incomplete stimuli as though they were complete (eg von der Heydt et al 1984), strongly indicating that perceptual completion and, thus, the formation of illusory 
form can be explained without a cognitive interpretation. Current psychophysical and animal behaviour studies likewise are focused on the question of how illusory figures may be generated at early stages of information processing. These new lines of research are guided by the idea that basic visual mechanisms can be integrated in a general perceptual theory of illusory form.

4 Visual psychophysics and neurophysiology: toward an integrative theory of illusory form Psychophysical experiments have provided a quantitative approach to the perception of illusory form which is complementary to the qualitative analysis of these phenomena by the Gestalt and cognitive approaches. Visual psychophysics is based on the premise that under certain conditions of stimulation the neurosensory basis of perceptual processes can be derived from behavioural data. Unlike purely phenomenological observations, psychophysical experiments are carried out under strictly controlled conditions of stimulation and measurement.

In an attempt to localise the mechanisms responsible for the Kanizsa and Ehrenstein illusions, researchers found that brightness enhancement and illusory contours disappear, or are severely impaired, when presented under conditions of equiluminance (Brigner and Gallagher 1974; Frisby and Clatworthy 1975; Spillmann et al 1976; Brussel et al 1977; Gregory 1977; Jory and Day 1979; Day 1987; Ejima and Takahashi 1988). This observation has been interpreted to suggest that illusory brightness may be induced relatively early in the visual system by a luminancecontrast mechanism. On the other hand, both the Kanizsa and the Ehrenstein illusions are present in stereoscopic vision (see findings on stereopsis in section 3.2) and can be perceived with dichoptic presentation of their component parts (Pastore 1971; Gregory 1972; Spillmann et al 1976). These results then suggest that the perception of illusory figures requires additional processing past the level of convergence of the two monocular inputs.

\subsection{The functional equivalence of real and illusory forms}

Bottom-up explanations of illusory form imply that, at some level, real and illusory forms must be functionally equivalent. This assumption finds support in a body of data showing that illusory-contour stimuli, in much the same way as real ones, produce tilt aftereffects and orientation masking (Smith and Over 1975, 1976, 1977; Paradiso et al 1989), motion aftereffects (Smith and Over 1979), apparent motion (Sigman and Rock 1974; von Grünau 1979; Ohmura 1981; Bradley and Lee 1982; Vallortigara 1987; Mather 1988), kinetic and stereokinetic effects (Kellman and Cohen 1984; Bressan and Vallortigara 1986; Ke'lman and Loukides 1987; Bruno and Gerbino 1991), as well as the oblique effect । oels and Orban 1987). Illusory contours have also been shown to be subject to and th roduce geometric illusions of the Orbinson, Poggendorff, Zöllner, Müller-Lyer, and Ponzo type (Farné 1968; Pastore 1971; Goldstein and Weintraub 1972; Gregory 1972; Day et al 1977; Kanizsa 1979; Meyer and Garges 1979; Meyer 1986). Last, objects and surfaces defined by illusory contours possess shape invariance and view stability, ie they retain their apparent shape despite changes in position and orientation in space relative to the observer (Petry and Gannon 1987; Vallortigara 1987; Carman and Welch 1992; see, however, Bradley 1987).

To demonstrate the physical reality of illusory contours and their equivalence with real contours, Ginsburg $(1975,1982,1987)$ subjected the Kanizsa figure to low-pass filtering. He demonstrated that after removal of the higher spatial frequencies, the dark triangle in the inverse Fourier transform was enhanced, especially at the boundaries, and therefore concluded that the low-spatial-frequency attenuation of the visual system may aid in the formation of the illusory triangle. This conclusion has been criticised on the grounds that it is questionable whether the output of two-dimensional 
spatial-frequency filtering directly reflects the output of the visual system, even at the earliest stages of processing (Tyler 1977; Becker and Knopp 1978; Parks and Pendergrass 1982). Nevertheless, the observation that optical blurring enhances the Ehrenstein illusion (Spillmann 1975; Brigner and Hammond 1981) supports the assumption that low-to-mid-bandpass filtering might operate in the production of brightness enhancement.

Recent psychophysical evidence for a functional equivalence of real and illusory contours comes from experiments in which it is shown that illusory contours give rise to subthreshold summation effects (Dresp and Bonnet 1995; Dresp and Grossberg 1995). The classic subthreshold summation is described by the fact that adding a nondetectable (subthreshold) line to a target line of the same polarity lowers the threshold for the detection of the target line (eg Kulikowski and King-Smith 1973). These findings suggest that the two kinds of lines are additive. The experiments by Dresp and collaborators show that subthreshold lines when presented on illusory contours become more easily detectable. Consequently, illusory-contour stimuli and real-line stimuli are likely to be processed by the same mechanism.

\subsection{Contrast mechanisms and brightness enhancement in illusory figures}

The idea that brightness enhancement in illusory figures might be a result of neural interactions which are known to underlie simultaneous-contrast phenomena (for a review, see Fiorentini 1972) has been discussed by Brigner and Gallagher (1974) and Frisby and Clatworthy (1975). However, this idea would need to explain why illusory surfaces can produce stronger brightness or darkness enhancement than areas which are completely surrounded by a contrasting black or white region (Coren and Theodor 1975; Parks et al 1983). Few attempts were made to test this hypothesis with the same psychophysical methods which were used to study classical brightness and darkness induction (Heinemann 1955, 1972; Jameson and Hurvich 1966): brightness matching, brightness cancellation, and increment-threshold measurement.

Spillmann et al (1984) used a matching and cancellation procedure to investigate brightness enhancement in the Ehrenstein illusion. Black-on-white and white-onblack inducing figures were tested. First, observers had to match the brightness or darkness of the illusory patch in the Ehrenstein figure to a comparison field presented on the surrounding background. Thereafter, they had to cancel the illusion by superimposing an appropriate test spot of opposite polarity. It was found that the luminance increment necessary to match the whiter-than-white effect was equivalent to the luminance decrement necessary to cancel the brightness enhancement. Both values were identical at $0.30 \mathrm{log}$ unit. The task was then repeated for darkness matching and cancellation in an Ehrenstein figure with all contrast signs reversed; here the corresponding values were $0.45 \mathrm{log}$ unit. This equivalence in size between matching and cancellation stimuli is not predicted by cognitive theory, but is consistent with the general assumption that the Ehrenstein illusion is produced by a neurophysiological mechanism. The results indicate, in fact, that the illusory patch behaves like a real luminance patch.

Measurements of induced darkness have recently been extended to the Kanizsa square (Dresp 1993). The increment needed to cancel out the blacker-than-black effect was found to increase with increasing luminance of the inducers according to a power function. This relationship suggests that brightness and darkness enhancement in the Kanizsa square may be explained on the basis of simultaneous contrast, in agreement with Brigner and Gallagher's (1974) hypothesis. A mechanism based on lateral interaction would also be compatible with the increase in the perceived strength of the illusion when the inducing stimuli are presented intermittently (Petry and Gannon 1987; Coren 1991; Siegel and Petry 1991). 
While matching and cancellation procedures provide consistent measures of the strength of illusory brightness enhancement, threshold measurements in the Kanizsa and Ehrenstein illusions have yielded paradoxical results. For example, despite the substantial changes in perceived brightness or darkness of the illusory area, decrement and increment thresholds for a small test spot presented in the centre of a Kanizsa square were not significantly different from thresholds obtained outside the illusory area (Coren and Theodor 1977; Dresp 1992). There was, however, a slight decrease when the target was flashed directly on one of the illusory borders (Dresp and Bonnet 1991, 1993; Dresp 1993). In the Ehrenstein illusion, Jory (1987) found a marked threshold decrease in the centre of the illusory area, but not on the illusory border (see Day and Jory 1980). These data are difficult to interpret.

A poor correlation between brightness and increment thresholds is known to exist from real contrast figures when the target was spatially separated from the border (Cornsweet and Teller 1965; van Esen and Novak 1974; Wildman 1974). This fact suggests that the threshold depends on a local mechanism, whereas brightness may be based on a global mechanism. Although illusory brightness may be triggered locally by the ends of lines (or edges), it can be expected that, eventually, it spreads out and fills in the area delineated by illusory contours (Gerrits and Vendrik 1970; Frisby and Clatworthy 1975; Spillmann et al 1976; Grossberg and Mingolla 1985; Grossberg 1994). Such a spreading would involve neural interactions between cells at increasingly higher levels of the visual system (Gerrits and Vendrik 1970; Gilbert and Wiesel 1985). Recent models of brightness induction demonstrate how such an integration of local contrasts into a global representation could work. Some attribute a central role to interactions between local feature detectors, others to symbolic interpretations of filter outputs at different spatial scales (for a review see Kingdom and Moulden 1992).

Further research is necessary to assess the role of contrast mechanisms in eliciting brightness or darkness in illusory forms. A psychophysical investigation of the polarity of the inducing elements would be particularly useful. One might ask whether inducers with opposite polarity can produce brightness or darkness enhancement. The idea here is that in figures combining both black and white inducers on a grey background, illusions should be weak or absent, since the two kinds of induction processes (brightness versus darkness) would cancel each other out. Actually, Prazdny $(1983,1985)$ has shown that in Ehrenstein figures composed of black and white inducers, brightness enhancement disappears, whereas illusory contours continue to be seen (see figure 7). Similar results have been recently obtained by

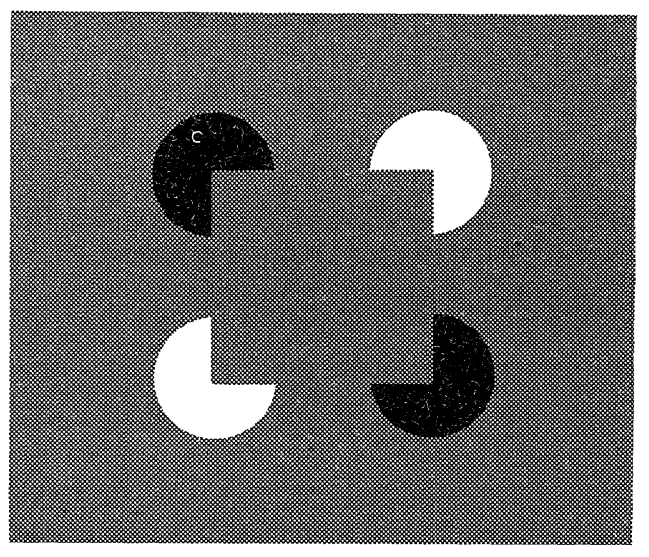

Figure 7. A Kanizsa square induced by 'pacmen' of opposite polarity. A weak illusory contour is seen, but no brightness enhancement (from Prazdny 1983). 
Dresp et al (in press) supporting the statement that brightness enhancement and illusory contours are probably independent and generated by separate mechanisms (see also Shapley and Gordon 1985, 1987).

\subsection{The neural basis of illusory contours}

Neurophysiological models based on receptive-field properties of simple, complex, and hypercomplex cells have been proposed earlier to account for brightness enhancement and neon colour spreading (Stadler and Dieker 1969, 1972; Jung 1973; Fuld and O'Donnell 1984; Redies et al 1984; Redies 1989). Notably, Stadler and Dieker suggested that cortical line detectors with partially stimulated receptive fields would produce a signal comparable to, but weaker than, the signal for a continuous line. The appearance of illusory stripes ('phantoms') moving through an empty gap in synchrony with two gratings halves on top and on the bottom (Tynan and Sekuler 1975; Fraser et al 1982) and the subsequent motion aftereffect resulting from this kind of stimulation (Weisstein et al 1977; Weisstein and Maguire 1978; Smith and Over 1979) could be perceptual correlates of such a mechanism. The fact that the motion aftereffect can be transferred from one eye to the other suggests that the underlying mechanism operates at or past the level of binocular integration in the visual cortex (Smith and Over 1979).

The 'triggering-of-line-detector' hypothesis has been questioned by Gregory (1972) and Gregory and Harris (1974) who point out that it cannot account for the occurrence of illusory contours such as in figures $2 \mathrm{c}$ and $2 \mathrm{~d}$. These are no easy figures to explain by a bottom - up approach. However, although there are still many questions that remain to be answered, one cannot dismiss the fascinating neurophysiological evidence that has accumulated over the last decade. Specifically, it was found that one third of the orientation-selective neurons in area V2 of the primate cortex (von der Heydt et al 1984) and in areas 17 and 18 of the cat (Redies et al 1986) respond to gap stimuli defined by collinear edges (Schumann) and to offset abutting gratings (Kanizsa) in much the same way as they do to real edges and contours (Peterhans and von der Heydt 1989, 1991; von der Heydt and Peterhans 1989a). Similar results have been recently reported for neurons in area V1 of the monkey (Grosof et al 1993; Lamme et al 1993). As in human perception (Spillmann 1975), the stimuli used in these studies became ineffective when small closing lines were added to their inducing ends, or when only one part of the stimulus was presented in the receptive field (Peterhans and von der Heydt 1989).

These findings suggest that binocular neural mechanisms selective to orientation may constitute the basis of illusory-contour perception. These mechanisms may involve cortical neurons with receptive fields collinear with the orientation of the inducing stimuli. Peterhans et al (1986) have presented a model for illusory-contour formation consisting of two pathways. The global 'grouping path' operates via a nonlinear mechanism which pools the responses of end-stopped cells in V1 signalling terminations orthogonal to the grouping direction. These neurons correspond to the hypercomplex cells of Hubel and Wiesel (1968). By comparison, the local 'edgedetecting path' consists of ordinary simple or complex cells tuned to the same orientation as the grouping direction. This dual input allows the contour cells to respond to real edges and lines as well as to stimuli eliciting illusory contours.

Cells signalling illusory lines or edges have been found in the pale and thick stripes, but not the thin stripes, of the cytochrome oxidase pattern of area V2 (Peterhans and von der Heydt 1991, 1993). These findings suggest that illusory contours might be attributed to the 'colour-blind', orientation-selective, interblob and magnocellular processing streams. Mediation by this pathway would be consistent with the absence of illusory contours at equiluminant colour contrast (Livingstone and 
Hubel 1988). However, it could not explain the sharp and crisp character of these contours, as the magnocellular system does not process high spatial frequencies.

Whatever the mechanism, there ought to be spatially defined limits to the neural interactions underlying the formation of illusory contours. Experiments have shown that the perceived strength of illusory contours in Kanizsa and Ehrenstein figures decreases with increasing gap size between the inducers (Dumais and Bradley 1976; Petry et al 1983; Bradley and Dumais 1984; Purghé and Katsaras 1991; Siegel and Petry 1991). This finding is consistent with the responses of V2 neurons (von der Heydt and Peterhans 1989a) and emphasises the importance of a spacing constraint in the neuronal grouping mechanism (Zucker and Davis 1988). However, it is difficult to reconcile with Shipley and Kellman's (1992b) hypothesis that the clarity of illusory contours depends on the 'support ratio', ie the ratio between physical edge length and total edge length, rather than on absolute gap size.

\section{Computational models and visual routines: algorithms that generate illusions}

Computational models of form perception have provided hypotheses about the ways in which a perceptual system might build up representations of form (real or illusory) on the basis of visual routines (eg Marr 1976, 1982). These routines are designed to extract local inputs, combine them, and integrate them into a global percept. Computational models have provided an important contribution to the theoretical framework of illusory-form perception. The algorithms for the simulation of visual processes and the theoretical concepts underlying these simulations constitute an invaluable source of inspiration for further experimental studies in the field.

With respect to illusory form, important theoretical contributions have come from a large number of researchers (Marr 1976, 1982; Ullman 1976, 1984; Cohen and Grossberg 1984; Grossberg and Mingolla 1985, 1987; Grossberg and Todorovic 1988; Finkel and Edelman 1989; Heitger and von der Heydt 1993; Grossberg 1994). Within these computational approaches it is assumed that illusory form results from the same mechanisms which account for the perception of real form, including specific operators for the processing of occlusion features. Surfaces and contours are processed in parallel by separate subsystems which, however, come to interact when a global representation of the stimulus is built up (see, in particular, Grossberg 1994). The mechanisms assumed to be involved here operate at a preattentive level of visual information processing. Visual form is seen as emerging from combinations of feature routines without the contribution of higher cognitive processes. The various models that have been proposed in the literature operate with different network constraints. Whereas the one by Heitger and von der Heydt (1993) is strictly feed-forward, others (Grossberg 1987a, 1987b) use feedback loops or reentrant connections (Finkel and Edelman 1989).

\subsection{A feature-processing system to account for brightness}

To account for illusory brightness and illusory contours in phenomena such as the Ehrenstein and Kanizsa illusions, in computational theories simulations of luminancespecific neural processes have been proposed. These simulations are based on inhibitory and excitatory interactions between cells whose receptive fields receive input from regions of luminance change. Luminance borders in this respect become 'feature contours' since they are assumed to trigger the featural process which is responsible for the emergence of differences in brightness or darkness between adjacent areas (Cohen and Grossberg 1984; Grossberg and Mingolla 1985, 1987; Grossberg 1994). This idea is related to Gerrits and Vendrik's (1970) neural model of simultaneous contrast, which shows how antagonistic activities of neurons with a centre-surround receptive-field organisation can explain why a dark region looks 
even darker when it is adjacent to a light area and why a bright region looks even brighter when it is adjacent to a dark field. Neurophysiological evidence for such an antagonistic behaviour was derived from single-cell recordings in the optic nerve and primary visual cortex of the cat [see the early work of Baumgartner $(1961,1964)$ and Jung (1961a, 1961b, 1964, 1973)].

Grossberg and Mingolla (1985, 1987) and Grossberg and Todorovic (1988) successfully simulated a featural process which is sensitive to the sign of contrast and triggers a filling-in of featural qualities such as brightness and colour. This diffusive process is assumed to extend over large areas away from luminance borders, depending on the local contrast available in the stimulus. Nearby boundaries will stop the diffusion abruptly (see Ullman 1984). Such a mechanism may explain why surfaces surrounded by fields of opposite polarity appear uniformly enhanced in brightness or darkness. According to Grossberg and colleagues, the diffusion of brightness or darkness at feature boundaries and the filling in of surfaces surrounded by boundary contours (real or illusory) operate at the same level of information processing. The filling in of bright or coloured surfaces is thus seen as a particular case of a locally triggered diffusive process.

\subsection{A boundary-processing system to account for illusory contours}

The process which is assumed to account for contour information is called the boundary-marking process by Ullman (1984), and the boundary-contour process by Grossberg et al (eg Grossberg and Mingolla 1985). This process is sensitive to orientation and contrast of a luminance border, but not to the polarity (or sign) of contrast. It uses the functional properties of higher cortical neurons, so-called complex cells (Hubel and Wiesel 1962, 1977), which respond to black as well as to white bars or edges. Figure 7 demonstrates that illusory contours can indeed be seen with inducing elements of oppposite contrast polarity.

The boundary-contour process synthesises boundaries from individual stimulus elements. The final representation is derived from these local inputs, which are progressively integrated into a global configuration through several stages of processing. The important idea here is that the oriented signal which is generated at the initial stage is preserved over the next stages. In this way, the gaps between collinearly arranged line ends and corners can be functionally completed (see also Ullman 1976). Grossberg and Mingolla (1985) propose that the output from short-range spatial interactions is then integrated into a further process involving long-range spatial interactions that allow the formation of boundaries over even-larger distances. This integration would account for the fact that illusory contours are perceived, although more weakly, even when the gaps between inducing elements are relatively large (see Ehrenstein 1941, 1954; Spillmann et al 1976). The boundary-contour model is consistent with neurophysiological findings in the monkey visual cortex (von der Heydt et al 1984; von der Heydt and Peterhans 1989a, 1989b; Peterhans and von der Heydt 1989, 1991).

A computational approach to contour mechanisms has also been proposed by Heitger and von der Heydt (1993). Their model accounts for the processing of luminance-defined and illusory contours by simulating the neurophysiologically determined responses of simple, complex, and end-stopped cells (Heitger et al 1992). As in the earlier work by Peterhans et al (1986), contour formation is achieved by an orientation-selective grouping process that collects the responses of end-stopped cells. Two types of end-stopped cells are distinguished (Peterhans, personal communication): single end-stopped cells (one inhibitory region) and double end-stopped cells (two inhibitory regions, at either end). For the grouping mechanism, only the signals of single-end-stopped cells are used. The authors assume that these cells signal the ends and corners (terminators) of stimuli as they typically occur in occlusion situations. 
An interesting aspect of this model is the differential processing of corner and line-end features. In the Kanizsa triangle, for example, illusory contours are generated parallel to, or collinear with, the inducing corners ('para grouping'), whereas in the case of the Ehrenstein illusion they are generated in a direction that is perpendicular to the inducing line ends ('ortho grouping'). Thus, the model accounts for a variety of illusory-contour shapes, including curved contours.

\subsection{Feature-boundary interactions and the formation of global percepts}

In the network model by Grossberg and collaborators, the feature process and the boundary process operate in parallel within two separate subsystems. However, to account for the integration of both brightness and contour information into a coherent percept of visual form, interactions between these two systems are necessary. Within the Grossberg logic, boundaries become visible only through featureboundary interactions ["all boundaries are invisible" (Grossberg and Mingolla 1987)]. In other words, it is assumed that contour cannot be perceived unless information about differences in brightness has been preprocessed. The interactions between brightness signals and boundary signals produce what the authors call a featureboundary trade-off (eg Grossberg and Mingolla 1985). The emergence of shape is achieved through activation of boundary operators which spatially block the diffusion generated by featural preprocessing. On the neural level, this may involve inhibitory signals from contour neurons which act as barriers to brightness signals (Ullman 1984; Grossberg and Mingolla 1985; Shapley and Gordon 1987; Grossberg 1994).

The Grossberg model also provides an explanation of neon colour spreading and transparency (see section 3.2). Whereas the earlier computational models were essentially concerned with local aspects of two-dimensional form perception, more-global aspects of information processing were also taken into account in the later developments of these models. Thus far the most complete model of preattentive form vision is Grossberg's FACADE ('form-and-colour-and-depth') theory (1994).

Unfortunately, psychophysicists and neurophysiologists continue to have difficulties with abstract computational concepts such as diffusion, filling in, or orthogonal pooling, to name a few. What precisely do these concepts mean in terms of neuronal mechanisms? How would these mechanisms influence our perception under specific conditions? How could the theories be tested? Clearly, the gap between models and empirical data cannot be bridged unless we have an answer to the most important question: to what extent can a simulation predict what we see?

\section{Conclusions}

In looking back on what has happened in the field over the last sixty years, one finds that Gestalt theory has provided knowledge of a general and lasting value for current approaches to illusory-form perception. However, the phenomenal descriptions in terms of visual and perceptual mechanisms were hardly sufficient, and the cognitive theories of the 1970 s and early 1980 s have likewise failed in that respect. Cognitive approaches have been successful in showing when and how the perception of illusory brightness and contours can vary, according to the physical stimulus or specific instructions, but they have not really helped us to understand the emergence of iliusory form. It seems that this can be achieved only by a theory that accounts for the processing both of local stimulus characteristics and of global perceptual processes. Such a theory does not yet exist.

The current stage of knowledge suggests that representations of illusory form must be available before a conscious interpretation of the stimulus takes place. Computational models have shown how such representations may be built up in the brain via competition and cooperation of visual neurons. Neurophysiological and psychophysical 
studies will show whether the empirical data prove the models right or wrong. The study of illusory form has only just begun and the principal challenge for future research is the investigation of the biological significance of illusory figures (Dresp, submitted).

\subsection{Different levels of explanation are complementary}

Although in this review we emphasise the role of preattentive, bottom-up mechanisms, we also allow for cognitive processes to modify illusory form perception. Illusory figures are often ambiguous. Many questions remain to be answered concerning the effects of attention and precueing on the perception of illusory form. Also, the close relationship between illusory-contour perception and the perception of partially occluded forms and objects in the real world should be investigated further (see Shipley and Kellman 1990, 1992a; Kellman and Shipley 1991).

The stages of processing required to build up a global representation of illusory form may perhaps be summarised as follows. Given the appropriate stimulus properties (local differences in luminance, collinearity), illusory-brightness and local-contour information are coded separately at a first stage of featural preprocessing (Day and Jory 1980; Ullman 1984; Grossberg and Mingolla 1985; Shapley and Gordon 1985; Dresp and Bonnet 1991). At a next stage, the spread of brightness is confined by illusory contours. Both are then integrated in a structural representation of figure and ground. The filling in of an illusory surface would occur in relation to figure-ground segregation (Dresp 1992). Although figure-ground organisation and filling in are likely to be determined by interactions between brightness and contour processes, they cannot be entirely cognition-free. Top-down effects of attentional factors (Bradley 1987), depth stratification (Coren 1972), and problem-solving strategies (Gregory 1972) need to be considered.

\subsection{Why does the brain generate illusory form?}

If we now ask the question, "why do we see illusory forms?", there are two possible answers. Some would say that these forms are invented [eg 'cognitive fictions' (Gregory, 1992)] by our cognitive system to solve a perceptual problem within a particular stimulus context. In this case, illusory forms would be a result of learning and experience. Others would say that illusory forms are the consequence of low-level visual processes, which fill in information where sensory input is partially lacking. In this case, the problem would be solved by a biological mechanism without us being aware of it. Both human and animal vision would benefit from such a mechanism.

Saying that illusory forms are intelligent constructs of human perception or considering that they are the result of biological adaptation implies that we make assumptions concerning the level at which these phenomena arise in the brain. Is the critical level the neurosensory one, or is it the cognitive one? Computational models capable of generating illusory contours lead us to suggest that low-level processes of form completion exist. However, as with real objects, cognitive processes may then generate the most likely percept within a given context. One of the main purposes of visual learning and cognition must be either to inhibit or to reinforce structural representations that were initially generated via preattentive mechanisms.

\subsection{Can we bridge the gap between levels of explanation?}

Most researchers in the domain of illusory-brightness perception now share the view that the perception of illusory figures must be based on some biological function (for a review see Dresp, submitted). However, there is still disagreement on how to approach this topic theoretically. In reviews on illusory contours and the associated brightness phenomena (eg Petry and Meyer 1987) the different viewpoints are categorised into bottom-up and top-down approaches, which implies that they are mutually exclusive. The message in this article is that they are not. Rather, holistic approaches 
on one hand and reductionistic approaches on the other must be considered complementary (see also Frisby and Clatworthy 1975; Pritchard 1986). Perceptually, a top - down signal may be as real as a bottom - up signal. Clearly, as our understanding of illusory phenomena progresses, the distinction between upward and downward processing becomes ever more difficult to define.

As already mentioned (section 2, page 1336, and section 4.3), a major challenge for a strictly neurosensory approach to illusory form is posed in figure $2 \mathrm{c}$, where each side of a hypothetical triangle is defined by only two end points and an open angle supporting it in the middle. Nevertheless, an illusory contour emerges. Another challenge is figure $2 \mathrm{~d}$, where the illusory contours are curvilinear, continuing in a direction different from that suggested by the straight-edged inducing contours (see also Kanizsa 1955, 1974, 1976, 1979). How could neurophysiological and computational mechanisms account for these effects? True, some end-stopped cells in the visual cortex of the cat are curvature selective (Dobbins et al 1987). But can they provide the neural basis for curved illusory contours like those shown in figure $2 \mathrm{~d}$ ?

Further examples to be explained are illusory surfaces that are slanted or bending in depth (Kanizsa 1974, 1976), hierarchies of stacked illusory figures (Ehrenstein 1941, 1954; Brigner and Gallagher 1974; Kanizsa 1974; Salzman and Halpern 1982), and three-dimensional objects such as the reversible illusory Necker cube (Piggins 1975; Bradley and Petry 1977). Nakayama and Shimojo's (1992) red cross embedded in a large white Ehrenstein figure also belongs here. Contrary to lateral disparity this figure elicits perception of a red transparent neon disc hovering above the large white cross. Are these effects representative of bottom-up processing, topdown processing, or both?

One may argue that we will never be able to explain fully all of the illusory brightness and contour percepts. At best, we might come close to it. By presenting rival approaches from phenomenology, cognition, single-cell recording, and visual computation and by suggesting how they may complement each other, in this article we want to show how an interdisciplinary approach is more likely to produce a complete and coherent body of evidence. Perhaps the pieces will eventually fit together and the question, "can we bridge the gap between levels of explanation?" will become obsolete. For the time being, however, the picture in the puzzle is only beginning to show.

Acknowledgements. This work was supported by Deutsche Forschungsgemeinschaft, SFB 325, B4. Parts of this manuscript were written while Lothar Spillmann was on leave of absence. He thanks Jack Werner and Beth Smith at the University of Colorado, Boulder, and Don MacLeod at the University of California, San Diego, for their support. The helpful comments of Claude Bonnet, Paola Bressan, Walter Ehrenstein, and Friedrich Heitger on earlier drafts of this manuscript are gratefully acknowledged. Special thanks to Pete Moss, Mitch Speaks, and Susan Menees who helped tidying it up and to two anonymous referees for their valuable suggestions.

\section{References}

Abravanel E, 1982 "Perceiving subjective contours during early childhood" Journal of Experimental Psychology 33 280-287

Albert M K, Hoffman D D, 1995 "Genericity in spatial vision", in Geometric Representations of Perceptual Phenomena: Papers in Honor of Tarow Indow's 70th Birthday Ed. D Luce (Hillsdale, NJ: Lawrence Erlbaum Associates) pp 95-112

Baumgartner G, 1961 "Die Reaktionen der Neurone des zentralen visuellen Systems der Katze im simultanen Helligkeitskonstrast", in Neurophysiologie und Psychophysik des Visuellen Systems Eds R Jung, H Kornhuber (Berlin: Springer) pp 296-313

Baumgartner G, 1962 "Zur Neurophysiologie und Psychophysik des simultanen Helligkeitskontrastes" Fortschritte der Medizin 80 633-638

Baumgartner G, 1964 "Neuronale Mechanismen des Kontrast- und Bewegungssehens" Berichte der Deutschen Ophthalmologischen Gesellschaft 66 111-125

Becker M F, Knopp J, 1978 "Processing of visual illusions in the frequency and spatial domains" Perception \& Psychophysics 23 521-526 
Bertenthal B I, Campos J, Haith M M, 1980 "Development of visual organization: The perception of subjective contours" Child Development 51 1072-1080

Bloomfield S, 1973 "Implicit feature and stereoscopy" Nature (London) 245256

Bradley D R, 1987 "Cognitive contours and perceptual organization", in The Perception of Illusory Contours Eds S Petry, G E Meyer (New York: Springer) pp 201-212

Bradley D R, Dumais S T, 1975 "Ambiguous cognitive contours" Nature (London) $257582-584$

Bradley D R, Dumais S T, 1984 "The effect of illumination level and retinal size on the depth stratification of subjective contour figures" Perception 13 155-164

Bradley D R, Lee K, 1982 "Animated subjective contours" Perception \& Psychophysics 32 393-395

Bradley D R, Mates S M, 1985 "Perceptual organization and apparent brightness in subjectivecontour figures" Perception 14 645-653

Bradley D R, Petry H M, 1977 "Organizational determinants of subjective contour: the subjective Necker cube" American Journal of Psychology $90253-262$

Bravo M, Blake R, Morrison S, 1988 "Cats see subjective contours" Vision Research 28 $861-865$

Bressan P, 1987 "Subjective rarefaction in illusory figures: The inadequacy of apparent lightness as an explanation" Perception $16461-466$

Bressan P, 1993 "Neon colour spreading with and without its figural prerequisites" Perception 22 $353-361$

Bressan P, Vallortigara G, 1986 "Subjective contours can produce stereokinetic effects" Perception 15 409-412

Brigner W L, Gallagher M B, 1974 "Subjective contour: Apparent depth or simultaneous brightness contrast" Perceptual and Motor Skills 38 1047-1053

Brigner W L, Hammond J T, 1981 "Role of brightness contrast and brightness contrast-reversal in illusory contour formation" Perceptual and Motor Skills 52 415-424

Bruno N, Bertamini M, 1990 "Identifying contours from occlusion events" Perception \& Psychophysics $48331-342$

Bruno N, Gerbino W, 1991 "Illusory figures based on kinematics" Perception 20 259-274

Brussel E M, Stober S R, Bodinger D M, 1977 "Sensory information and subjective contour" American Journal of Psychology $90145-156$

Carman G J, Welch L, 1992 "Three-dimensional illusory contours and surfaces" Nature (London) $360585-587$

Cohen M A, Grossberg S, 1984 "Neural dynamics of brightness perception: features, boundaries, diffusion, and resonance" Perception \& Psychophysics 36 428-456

Corbetta M, Antonini A, Berlucchi G, Aglioti S, 1989 "Texture discrimination and illusory contour perception in normal and decorticated cats" Pflügers Archiv (European Journal of Physiology) 41461

Coren S, 1972 "Subjective contours and apparent depth" Psychological Review 79 359-367

Coren S, 1991 "Retinal mechanisms in the perception of subjective contours: the contribution of lateral inhibition" Perception 20 181-191

Coren S, Porac C, 1983 "Subjective contours and apparent depth: A direct test" Perception \& Psychophysics 33 197-200

Coren S, Porac C, Theodor L H, 1987 "Set and subjective contour", in The Perception of Illusory Contours Eds S Petry, G E Meyer (New York: Springer) pp 237-245

Coren S, Theodor L H, 1975 "Subjective contour: The inadequacy of brightness contrast as an explanation" Bulletin of the Psychonomic Society 687 - 89

Coren S, Theodor L H, 1977 "Neural interactions and subjective contours" Perception 6 107-111

Cornsweet T N, Teller D Y, 1965 "Relation of increment thresholds to brightness and luminance" Journal of the Optical Society of America 55 1303-1308

Day R H, 1986 "Enhancement of edges by contrast, depth and figure: The origin of illusory contours", in Visual Neuroscience Eds J D Pettigrew, K J Sanderson, W R Levick (Cambridge: Cambridge University Press) pp 352-364

Day R H, 1987 "Cues for edge and the origin of illusory contours: An alternative approach", in The Perception of Illusory Contours Eds S Petry, G E Meyer (New York: Springer) pp 53-61

Day R H, Dickinson R G, Jory M K, 1977 "The Poggendorff illusion with subjective contours" Quarterly Journal of Experimental Psychology 29 219-226

Day R H, Jory M K, 1978 "Subjective contours, visual acuity, and line contrast", in Visual Psychophysics and Physiology Eds J C Armington, J Krauskopf, B R Wooten (New York: Academic Press) pp 331-340 
Day R H, Jory M K, 1980 "A note on a second stage in the formation of illusory contours" Perception \& Psychophysics 27 89-91

Day R H, Kasperczyk R T, 1983a "Amodal completion as a basis for illusory contours" Perception \& Psychophysics 33 355-364

Day R H, Kasperczyk R T, 1983b "Illusory contours in line patterns with apparent depth due to either perspective or overlay" Perception 12 485-490

Dobbins A, Zucker S W, Cynader M S, 1987 "Endstopped neurons in the visual cortex as a substrate for calculating curvature" Nature (London) 329 438-441

Doorn A J van, Koenderink J J, 1982 "Visibility of movement gradient" Biological Cybernetics $44167-175$

Dresp B, 1992 "Local mechanisms sketch out surfaces, but do not fill them in: Evidence in the Kanizsa square" Perception \& Psychophysics 52 562-570

Dresp B, 1993 "Bright lines and edges facilitate the detection of small light targets" Spatial Vision 7 213-225

Dresp B, submitted, "On the biological significance of figures with illusory contours: Physiological and psychological aspects" Psychonomic Bulletin \& Review

Dresp B, Bonnet C, 1991 "Psychophysical evidence for low-level processing of illusory contours and surfaces in the Kanizsa square" Vision Research 10 1813-1817

Dresp B, Bonnet C, 1993 "Psychophysical measures of illusory form perception: Further evidence for local mechanisms" Vision Research 33 759-766

Dresp B, Bonnet C, 1995 "Subthreshold summation with illusory contours" Vision Research 35 $1071-1078$

Dresp B, Grossberg S, 1995 "Illusory-contour integration: From contrast summation to bipole cooperation" Perception 24 Supplement, 30

Dresp B, Lorenceau J, Bonnet C, 1990 "Apparent brightness enhancement in the Kanizsa square with and without illusory contours" Perception 19 483-489

Dresp B, Pardieu V, Bonnet C (in press) "Illusory form from inducers with opposite contrast polarity: Evidence for multistage integration mechanisms" Perception \& Psychophysics

Dumais S T, Bradley D R, 1976 "The effects of illumination level and retinal size on the apparent strength of subjective contours" Perception \& Psychophysics $19339-345$

Ehrenstein W, 1941 "Über Abwandlungen der L. Hermannschen Helligkeitserscheinung" Zeitschrift für Psychologie 150 83-91 ["Modifications of the brightness phenomenon of L. Hermann"; translation by A Hogg, 1987, in The Perception of Illusory Contours Eds S Petry, G E Meyer (New York: Springer) pp 35-39]

Ehrenstein W, 1954 Probleme der ganzheitspsychologischen Wahrnehmungslehre (Leipzig: Barth)

Ejima Y, Takahashi S, 1988 "Illusory contours induced by chromatic patterns" Vision Research $281367-1377$

Enns J T, Rensink R A, 1993 "A model for the rapid interpretation of line drawings in early vision", in Visual Search II: Proceedings of the Second International Conference on Visual Search Eds D Brogan, A Gale, K Carr (London: Taylor and Francis) pp 73-89

Enns J T, Rensink R A, 1994 "An object completion process in early vision", in Visual Search III: Proceedings of the Third International Conference on Visual Search Eds A G Gale (London: Taylor and Francis)

Esen J S van, Novak S, 1974 "Detection thresholds within a display that manifests contour enhancement and brightness contrast" Journal of the Optical Society of America 64 726-729

Farné M, 1968 "Alcune osservazioni con linee virtuali e margini quasi percettivi" Bollettino della Società Italiana de Biologia Sperimentale $441613-1616$

Field D J, Hayes A, Hess R F, 1993 "Contour integration by the human visual system: evidence for a local 'association field'" Vision Research 33 173-193

Finkel L H, Edelman G M, 1989 "Integration of distributed cortical systems by reentry: a computer simulation of interactive functionally segregated visual areas" Journal of Neuroscience $93188-3208$

Fiorentini A, 1972 "Mach band phenomena", in Handbook of Sensory Physiology volume 7 Visual Psychophysics Eds D Jameson, L M Hurvich (New York: Springer) pp 188-201

Fraser A S, 1983 "Ehrenstein variations" Perception 12 143-147

Fraser A, Wilcox K, Storing S, 1982 "The filling-in illusion and moving visual phantoms" Perceptual and Motor Skills $54343-355$

Frisby J P, 1979 Seeing: Illusion, Brain, and Mind (Oxford: Oxford University Press)

Frisby J P, Clatworthy J L, 1975 "Illusory contours: Curious cases of simultaneous brightness contrast?" Perception 4 349-357 
Fuld K, O'Donnell K, 1984 "Brightness matching and scaling of the Ehrenstein illusion", in Sensory Experience, Adaptation, and Perception Eds L Spillmann, B Wooten (Hillsdale, NJ: Lawrence Erlbaum Associates) pp 461 - 469

Galli A, Hochheimer W, 1934 "Beobachtungen an Nachzeichnungen mehrdeutiger Feldkonturen" Zeitschrift für Psychologie 132304 - 334

Gerbino W, Kanizsa G, 1987 "Can we see constructs?", in The Perception of Illusory Contours Eds S Petry, G E Meyer (New York: Springer) pp 246-252

Gerrits H J M, Vendrik A J H, 1970 "Simultaneous contrast filling-in process and information processing in man's visual system" Experimental Brain Research 11411 - 430

Ghim H R, 1990 "Evidence for perceptual organization in infants: Perception of subjective contours by young infants" Infant Behavior and Development 13221 - 248

Gilbert C D, Wiesel T N, 1985 "Intrinsic connectivity and receptive field properties in the visual cortex" Vision Research 25365 - 374

Gillam B, 1987 "Perceptual grouping and subjective contours", in The Perception of Illusory Contours Eds S Petry, G E Meyer (New York: Springer) pp 268-273

Ginsburg A P, 1975 "Is the illusory triangle physical or imaginary?" Nature (London) 257 $219-220$

Ginsburg A P, 1982 "On a filter approach to understanding the perception of visual form", in Recognition of Pattern and Form Ed. D G Albrecht (New York: Springer) pp 175-192

Ginsburg A P, 1987 "The relationship between spatial filtering and subjective contours", in The Perception of Illusory Contours Eds S Petry, G E Meyer (New York: Springer) pp 126 - 130

Goldstein M B, Weintraub D J, 1972 "The parallel-less Poggendorff: Virtual contours put the illusion down, but not out" Perception \& Psychophysics 11 353-355

Gollin E S, 1960 "Developmental studies of visual recognition of incomplete objects" Perceptual and Motor Skills $11289-298$

Gregory R L, 1966 Eye and Brain (London: Weidenfeld and Nicolson) (4th edition reprinted 1994, Oxford: Oxford University Press)

Gregory R L, 1970 The Intelligent Eye (New York: McGraw-Hill)

Gregory R L, 1972 “Cognitive contours" Nature (London) 23851 - 52

Gregory R L, 1973 "The confounded eye", in Illusions in Nature and Art Eds R L Gregory, E H Gombrich (London: Gerald Duckworth) pp 49-95

Gregory R L, 1974 Concepts and Mechanisms of Perception (New York: Scribner)

Gregory R L, 1977 "Vision with isoluminant colour contrast: 1. A projection technique and observations" Perception 6 113-119

Gregory R L, 1980 "Perceptions as hypotheses" Philosophical Transactions of the Royal Society of London, Series B 290181 - 197

Gregory R L, 1986 "Illusory surfaces as perceptual postulates" Perception \& Psychophysics 39 220

Gregory R L, 1987 "Illusory contours and occlusion surfaces", in The Perception of Illusory Contours Eds S Petry, G E Meyer(New York: Springer) pp 81 - 89

Gregory R L, 1992 "Classifying visual phenomena" Perception 21 Supplement, 70

Gregory R L, Harris J P, 1974 "Illusory contours and stereo depth" Perception \& Psychophysics $15411-416$

Grosof D H, Shapley R M, Hawken M J, 1993 "Macaque V1 neurons can signal illusory contours" Nature (London) $365550-552$

Grossberg S, 1987a "Cortical dynamics of three-dimensional form, color, and brightness perception: 1. Monocular theory" Perception \& Psychophysics 41 87-116

Grossberg S, 1987b "Cortical dynamics of three-dimensional form, color, and brightness perception: II. Binocular theory" Perception \& Psychophysics 41 117-158

Grossberg S, 1994 "3-D vision and figure-ground separation by visual cortex" Perception \& Psychophysics 55 48-120

Grossberg S, Mingolla E, 1985 "Neural dynamics of form perception: Boundary completion, illusory figures, and neon color spreading" Psychological Review 92 173-211

Grossberg S, Mingolla E, 1987 "The role of illusory contours in visual segmentation", in The Perception of Illusory Contours Eds S Petry, G E Meyer(New York: Springer) pp 116-125

Grossberg S, Todorovic D, 1988 "Neural dynamics of 1-D and 2-D brightness perception: A unified model of classic and recent phenomena" Perception \& Psychophysics $43241-277$

Grünau M von, 1979 "The involvement of illusory contours in stroboscopic motion" Perception \& Psychophysics 25 205-208

Gurnsey R, Humphrey G K, Kapitan P, 1992 "Parallel discrimination of subjective contours defined by offset gratings" Perception \& Psychophysics 52 263-276 
Halpern D F, 1981 "The determinants of illusory-contour perception" Perception 10 199-213

Halpern D F, 1987 "The functional equivalence of objective and illusory brightness enhancement", in The Perception of Illusory Contours Eds S Petry, G E Meyer (New York: Springer) pp $171-175$

Halpern D F, Salzman B, 1983 "The multiple determination of illusory contours: 1. A review Perception $12281-291$

Halpern D F, Salzman B, Harrison W, Widaman K, 1983 "The multiple determination of illusory contours: 2. An empirical investigation" Perception 12 293-303

Harris J P, Gregory R L, 1973 "Fusion and rivalry of illusory contours" Perception 2 235-247

Hateren J H, Srinivasan M V, Wait P B, 1990 "Pattern recognition in bees: orientation discrimination" Journal of Comparative Physiology 167 649-654

Heinemann E G, 1955 "Simultaneous brightness induction as a function of inducing and testfield luminances" Journal of Experimental Psychology 50 89-96

Heinemann E G, 1972 "Simultaneous brightness induction", in Handbook of Sensory Physiology volume 7 Visual Psychophysics Ed. D Jameson, L M Hurvich (New York: Springer) pp 146-169

Heitger F, Heydt R von der, 1993 "A computational model of neural contour processing: figure-ground segregation and illusory contours" Proceedings of the 4th International Conference on Computer Vision pp 32-40

Heitger F, Rosenthaler L, Heydt R von der, Peterhans E, Kübler O, 1992 "Simulation of neural contour mechanisms: From simple to end-stopped cells" Vision Research 32963 - 981

Hering E, 1878 Zur Lehre vom Lichtsinn (Vienna: Gerolds Söhne)

Hershberger W, Stallard S, 1984 "Contrast variability lightens subjective figures" Perception \& Psychophysics 36 92-94

Heydt R von der, Peterhans E, 1989a "Mechanisms of contour perception in monkey visual cortex. I: Lines of pattern discontinuity" Journal of Neuroscience $91731-1748$

Heydt R von der, Peterhans E, 1989b "Ehrenstein and Zöllner illusions in a neuronal theory of contour processing", in Seeing Contour and Colour Eds J J Kulikowski, C M Dickinson, I J Murray (Oxford: Pergamon Press) pp 729-734

Heydt R von der, Peterhans E, Baumgartner G, 1984 "Illusory contours and cortical neuron responses" Science $2241260-1262$

Horridge G A, Zhang S-W, O'Carroll D, 1992 "Insect perception of illusory contours" Philosophical Transactions of the Royal Society of London, Series B 337 59-64

Hubel D H, Wiesel T N, 1962 "Receptive fields, binocular interaction and functional architecture in the cat's visual cortex" Journal of Physiology (London) 160 106-154

Hubel D H, Wiesel T N, 1968 "Receptive fields and functional architecture of monkey striate cortex" Journal of Physiology (London) 195 215-243

Hubel D H, Wiesel T N, 1977 "Functional architecture of macaque monkey visual cortex" Proceedings of the Royal Society of London, Series B 198 1-59

Jameson D, Hurvich L M, 1966 The Perception of Brightness and Darkness. Contemporary Topics in Experimental Psychology (Boston, MA: Allyn and Bacon)

Jory M K, 1987 "Increment thresholds in illusory contour line patterns", in The Perception of Illusory Contours Eds S Petry, G E Meyer (New York: Springer) pp 183-189

Jory M K, Day R H, 1979 "The relationship between brightness contrast and illusory contours" Perception 8 3-9

Julesz B, 1971 Foundations of Cyclopean Perception (Chicago, IL: University of Chicago Press)

Julesz B, Frisby J P, 1975 "Some new subjective contours in random-line stereograms" Perception $4145-150$

Jung R, 1961a "Neuronal integration in the visual cortex and its significance for visual information", in Sensory Communication Ed. W Rosenblith (Cambridge, MA: MIT Press) pp 627-674

Jung R, 1961b "Korrelationen von Neuronentätigkeit und Sehen", in Neurophysiologie und Psychophysik des Visuellen Systems Eds R Jung, H Kornhuber (Berlin: Springer) pp 410 - 435

Jung R, 1964 "Neuronale Grundlagen des Hell-Dunkel-Sehens und der Farbwahrnehmung" Berichte der Deutschen Ophthalmologischen Gesellschaft 66 69-111

Jung R, 1973 "Visual perception and neurophysiology", in Handbook of Sensory Physiology volume 7/3, part A Central Visual Information Ed. R Jung (Berlin: Springer) pp 1-152

Kanizsa G, 1955 "Margini quasi-percettivi in campi con stimolazione omogenea" Rivista di Psicologia 49 7-30 ["Quasiperceptual margins in homogeneously stimulated fields"; translation by W Gerbino, 1987, in The Perception of Illusory Contours Eds S Petry, G E Meyer (New York: Springer) pp 40-49]

Kanizsa G, 1974 "Contours without gradients or cognitive contours?” Italian Journal of Psychology $193-112$ 
Kanizsa G, 1976 "Subjective contours" Scientific American 23448 - 52

Kanizsa G, 1979 Organization in Vision: Essays on Gestalt Perception (New York: Praeger)

Kanizsa G, Caramelli N, 1988 L'eredità della psicologia della gestalt (Bologna: Il Mulino)

Kellman PJ, Cohen M H, 1984 "Kinetic subjective contours" Perception \& Psychophysics 35 $237-244$

Kellman PJ, Loukides M G, 1987 "An objective perception approach to static and kinetic subjective contours", in The Perception of Illusory Contours Eds S Petry, G E Meyer (New York: Springer) pp 151-164

Kellman P J, Shipley T F, 1991 "A theory of visual interpolation in object perception" Cognitive Psychology 23 141-221

Kennedy J M, 1975 "Depth at an edge, coplanarity, slant depth, change in direction and change in brightness in the production of subjective contours" Italian Journal of Psychology 2 $107-123$

Kennedy J M, 1976a "Attention, brightness, and the constructive eye", in Vision and Artifact Ed. M Henle (New York: Springer) pp 33-48

Kennedy J M, 1976b "Sun figure: An illusory diffuse contour resulting from an arrangement of dots" Perception 5 479-481

Kennedy J M, 1978a "Illusory contours not due to completion" Perception 7 187-189

Kennedy J M, 1978b "Illusory contours and the ends of lines" Perception 7 605-607

Kennedy J M, 1979 "Subjective contours, contrast and assimilation", in Perception and Pictorial Representation Eds C Nodine, D F Fisher (New York: Praeger) pp 167-195

Kennedy J M, 1981 "Illusory brightness and the ends of petals: change in brightness without aid of stratification or assimilation effects" Perception 10 583-585

Kennedy J M, 1988 "Line endings and subjective contours" Spatial Vision 3151 -158

Kennedy J M, Chattaway D, 1975 "Subjective contours, binocular and movement phenomena" Italian Journal of Psychology 2 355-367

Kennedy J M, Lee H, 1976 "A figure-density hypothesis and illusory contour brightness" Perception 5 387-392

Kennedy J M, Ware C, 1978 "Illusory contours can arise in dot figures" Perception 7191 -194

Kingdom F, Moulden B, 1992 "A multi-channel approach to brightness coding" Vision Research $321565-1582$

Koffka K, 1935 Principles of Gestalt Psychology (New York: Harcourt, Brace)

Köhler W, 1940 Dynamics in Psychology (New York: Liveright)

Kulikowski J J, King-Smith P E, 1973 "Spatial arrangement of line, edge and grating detectors revealed by subthreshold summation" Vision Research 13 1455-1478

Lamme V A F, Dijk B W van, Spekreijse H, 1993 "Contour from motion processing occurs in primary visual cortex" Nature (London) 363 541-543

Landauer A A, 1978 "Subjective states and the perception of subjective contours", in Conceptual Analysis and Method in Psychology: Essays in Honor of W. M. O'Neil Ed. J P Sutcliffe (Sydney: Sydney University Press) pp 142-146

Lawson R B, Cowan E, Gibbs T D, Whitmore C G, 1974 "Stereoscopic enhancement and erasure of subjective contours" Journal of Experimental Psychology 103 1142-1146

Lawson R B, Gulick W L, 1967 "Stereopsis and anomalous contour" Vision Research 7 $271-297$

Legrenzi P, 1988 "La psicologia gestaltista del pensiero nella cultura tedesca e in quella americana", in L'eredità della Psicologia della Gestalt Eds G Kanizsa, N Caramelli (Bologna: Il Mulino) pp 53-71

Lesher G W, Mingolla E, 1993 "The role of edges and line-ends in illusory contour formation" Vision Research 33 2253-2270

Livingstone M, Hubel D, 1988 "Segregation of form, color, movement, and depth: Anatomy, physiology and perception" Science $240740-749$

Mach E, 1865-1868 "Über die Wirkung der räumlichen Verteilung des Lichtreizes auf der Netzhaut" Sitzungsberichte der Wiener Akademie der Wissenschaften, Mathematisch-naturwissenschaftliche Classe, Zweite Abteilung 52 303-322

Marr D, 1976 "Early processing of visual information" Philosophical Transaction of the Royal Society of London, Series B 275 483-519

Marr D, 1982 Vision. A Computational Investigation into the Human Representation and Processing of Visual Information (San Francisco, CA: W H Freeman)

Masini R, Perussia F, 1983 "Margini anomali netti e margini anomali sfumati: Un'analisi multivariata”, in Reports from the Institute of Psychology (Milan: University of Milan) pp 1-21 
Mather G, 1988 "Temporal properties of apparent motion in subjective figures" Perception 17 $729-736$

Metzger W, 1953 Gesetze des Sehens 2nd edition (Frankfurt: W Kramer)

Meyer GE, 1986 "Interactions of subjective contours with the Ponzo, Müller-Lyer, and vertical - horizontal illusions" Bulletin of the Psychonomic Society $2439-40$

Meyer G E, Dougherty T, 1987 "Effects of flicker-induced depth on chromatic subjective contours" Journal of Experimental Psychology: Human Perception and Performance 13353 - 360

Meyer G E, Garges C, 1979 "Subjective contours and the Poggendorff illusion" Perception \& Psychophysics $26302-304$

Meyer G E, Petry S, 1987 "Top-down and bottom-up. The illusory contour as a microcosm of issues in perception", in The Perception of Illusory Contours Eds S Petry, G E Meyer (New York: Springer) pp 3-20

Minguzzi G F, 1982 "Figure anomale: le modificazioni di chiarezza indotte da fine di linea", report from the Institute of Psychology, Trieste

Minguzzi G F, 1984 "La percezione di superfici anomale", in Fenomenologia Sperimentale della Visione Ed. G Kanizsa (Milan: F Angeli) pp 97-118

Mori G F, 1959 "Is it possible to measure the contrast enhancement of a figure with "quasiperceptive contours'?" Atti della Fondazione Giorgio Ronchi 14137 -139

Mori G F, Ronchi L, 1960 "On the perception of incomplete borders" Atti della Fondazione Giorgio Ronchi $15357-368$

Mustillo P, Fox R, 1986 "The perception of illusory contours in the hypercyclopean domain" Perception \& Psychophysics $40362-363$

Nakayama K, Shimojo S, 1990 "Toward a neural understanding of visual surface representation", in Cold Spring Harbor Symposium on Quantitative Biology volume 40 The Brain Eds T Sejnowski, E R Kandel, C F Stevens, J D Watson (Cold Spring Harbor, NY: Cold Spring Harbor Laboratory) pp $911-924$

Nakayama K, Shimojo S, 1992 "Experiencing and perceiving visual surfaces" Science 257 $1357-1363$

Nakayama K, He Z J, Shimojo S, 1995 "Visual surface representation: A critical link between lower-level and higher-level vision", in An Invitation to Cognitive Science volume 2 Visual Cognition Eds S M Kosslyn, D N Osherson(Cambridge, MA: MIT Press) pp 1 - 70

Nakayama K, Shimojo S, Ramachandran V S, 1990 "Transparency: relation to depth, subjective contours, luminance, and neon color spreading" Perception 19 497- 513

Ohmura H, 1981 "Effects of subjective contours in stroboscopic motion" Japanese Journal of Psychology 52 233-239

Paradiso M A, Shimojo S, Nakayama K, 1989 "Subjective contours, tilt aftereffects, and visual cortical organization" Vision Research 291205 -1213

Parks T E, 1979 "Subjective figures: Does brightness enhancement depend on subjective boundary definition?" Perception \& Psychophysics 26419

Parks T E, 1980a "The subjective brightness of illusory figures: Is stratification a factor?" Perception $9361-363$

Parks T E, 1980b "Letter to the Editor" Perception 9723

Parks T E, 1982 "Brightness effects in diffuse and sharp illusory figures of similar configuration" Perception 11 107-110

Parks T E, 1986 "Illusory figures, illusory objects, and real objects" Psychological Review 93 $207-215$

Parks T E, 1987 "Illusory figures and pictorial objects", in The Perception of Illusory Contours Eds S Petry, G E Meyer (New York: Springer) pp 76-80

Parks T E, 1989 "Illusory figure-lightness: Evidence for a two-component theory" Perception 18 $783-788$

Parks T E, Pendergrass L, 1982 "On the filtered-components approach to illusory visual contours" Perception \& Psychophysics 32491 - 493

Parks T E, Rock I, Anson R, 1983 "Illusory contour lightness: a neglected possibility" Perception $1243-47$

Pastore N, 1971 Selective History of Theories of Visual Perception 1650-1950 (New York: Oxford University Press)

Peterhans E, Heydt R von der, 1989 "Mechanisms of contour perception in monkey visual cortex. II: Contours bridging gaps" Journal of Neuroscience 9 1749-1763

Peterhans E, Heydt R von der, 1991 "Subjective contours-bridging the gap between psychophysics and physiology" Trends in Neuroscience $14112-119$ 
Peterhans E, Heydt R von der, 1993 "Functional organization of area V2 in the alert monkey" European Journal of Neuroscience 5 509-524

Peterhans E, Heydt R von der, Baumgartner G, 1986 "Neuronal responses to illusory contour stimuli reveal stages of visual cortical processing", in Visual Neuroscience Eds J D Pettigrew, K J Sanderson, W R Levick (Cambridge: Cambridge University Press) pp 343-351

Petry S, Gannon R, 1987 "Time, motion, and objectness in illusory contours", in The Perception of Illusory Contours Eds S Petry, G E Meyer (New York: Springer) pp 193-200

Petry S, Meyer G E (Eds), 1987 The Perception of Illusory Contours (New York: Springer)

Petry S, Harbeck A, Conway J, Levey J, 1983 "Stimulus determinants of brightness and distinctness of subjective contours" Perception \& Psychophysics 34 169-174

Piggins D J, 1975 "Cognitive space" Perception 4 337-340

Prandtl A, 1927 "Über gleichsinnige Induktion und die Lichtverteilung in gitterartigen Mustern" Zeitschrift für Sinnesphysiologie 58 263-307

Prazdny K, 1983 "Illusory contours are not caused by simultaneous brightness contrast" Perception \& Psychophysics 34 403-404

Prazdny K, 1985 "On the nature of inducing forms generating perceptions of illusory contours" Perception \& Psychophysics 37 237-242

Pritchard W S, 1986 "Reductionism versus holism: levels of explanation and the subjective contour illusion" Perception \& Psychophysics 39214

Pritchard W S, Warm J S, 1983 "Attentional processing and the subjective contour illusion" Journal of Experimental Psychology: General 112 145-175

Purghé F, 1988 "The role of figural incompleteness and brightness contrast in the formation of anomalous surfaces" Perception 17365

Purghé F, 1991 "Is amodal completion necessary to the formation of illusory figures?" Perception $20623-636$

Purghé F, Coren S, 1992 "Subjective contours 1900-1990: Research trends and bibliography" Perception \& Psychophysics $\mathbf{5 1} 291-304$

Purghé F, Katsaras P, 1991 "Figural conditions affecting the formation of anomalous surfaces: An overall configuration versus a simple stimulus part" Perception 20 193-206

Ramachandran V S, 1985 "Apparent motion of subjective surfaces" Perception 14 127-134

Ramachandran V S, 1986 "Capture of stereopsis and apparent motion by illusory contours" Perception \& Psychophysics $39361-373$

Ramachandran V S, 1987 "Visual perception of surfaces: A biological theory", in The Perception of Illusory Contours Eds S Petry, G E Meyer (New York: Springer) pp 92-108

Ramachandran V S, 1992 "Perception: A biological perspective", in Neural Networks for Vision Image Processing Eds G A Carpenter, S Grossberg (Cambridge, MA: MIT Press) pp 45-91

Ramachandran V S, Cavanagh P, 1985 "Subjective contours capture stereopsis" Nature (London) $317527-530$

Ramachandran V S, Inada V, 1984 "Motion capture in random-dot patterns" Optics News 10(5) 77

Redies C, 1989 "Discontinuity along lines: Psychophysics and neurophysiology" Neuroscience \& Biobehavioural Reviews 13 17-22

Redies C, Crook J M, Creutzfeldt O D, 1986 "Neuronal responses to borders with and without luminance gradients in cat visual cortex and dorsal lateral geniculate nucleus" Experimental Brain Research $61469-481$

Redies C, Spillmann L, 1981 "The neon color effect in the Ehrenstein illusion" Perception 10 $667-681$

Redies C, Spillmann L, Kunz K, 1984 "Colored neon flanks and line gap enhancement" Vision Research $241301-1309$

Reynolds R I, 1981 "Perception of an illusory contour as a function of processing time" Perception $10107-115$

Richardson B L, 1979 "The nonequivalence of abrupt and diffuse illusory contours" Perception $8589-593$

Richardson B L, Wuillemin D B, 1981 "Illusory contours not accompanied by a brightness gradient" Italian Journal of Psychology $8201-207$

Rieth C, Sireteanu R, 1993 "How do infants perceive subjective contours?" poster at the 4th Meeting of the Child Vision Research Society, Lyon, 11 - 13 July, available from R Sireteanu

Rock I, 1987 "A problem solving approach to illusory contours", in The Perception of Illusory Contours Eds S Petry, G E Meyer (New York: Springer) pp $62-70$

Rock I, Anson R, 1979 "Illusory contours as the solution to a problem" Perception 8 665-681 
Ronchi L, Mori G F, 1959 "On the factors which affect the contrast enhancement in a figure with 'quasi-perceptive contours' and a practical application of such a figure" Atti della Fondazione Giorgio Ronchi 14495 - 508

Rubin E, 1921 Visuell Wahrgenommene Figuren (Copenhagen: Gyldendals)

Salzman B, Halpern D F, 1982 "Subjective towers: depth relationships in multilevel subjective contours" Perceptual and Motor Skills 55 1247-1256

Sambin M, 1975 "The role of terminal tensions in the organization of margins without gradients" Italian Journal of Psychology 2 239-257

Sambin M, 1977 "Contours without gradient with different phenomenal evidence" Italian Journal of Psychology $4121-147$

Sambin M, 1987 "A dynamic model of anomalous figures", in The Perception of Illusory Contours Eds S Petry, G E Meyer (New York: Springer) pp 131-142

Schumann F, 1900 "Einige Beobachtungen über die Zusammenfassung von Gesichtseindrücken zu Einheiten" Zeitschrift für Psychologie 23 1-32 [reprinted 1904 Psychologische Studien 1 1-32; translation by A Hogg, 1987, "Some observations on the combination of visual impressions into units", in The Perception of Illusory Contours Eds S Petry, G E Meyer (New York: Springer) pp 21-34]

Sekuler A B, Palmer S E, 1992 "Perception of partly occluded objects: A microgenetic analysis" Journal of Experimental Psychology, General 121 95-111

Shapley R, Gordon J, 1985 "Nonlinearity in the perception of form" Perception \& Psychophysics $3784-88$

Shapley R, Gordon J, 1987 "The existence of interpolated illusory contours depends on contrast and spatial separation", in The Perception of Illusory Contours Eds S Petry, G E Meyer (New York: Springer) pp 109-115

Shipley T, 1965 "Visual contours in homogeneous space" Science $150348-350$

Shipley T F, Kellman P J, 1990 "The role of discontinuities in the perception of subjective figures" Perception \& Psychophysics 48 259-270

Shipley T F, Kellman P J, 1992a "Perception of partly occluded objects and illusory figures: Evidence for an identity hypothesis" Journal of Experimental Psychology: Human Perception and Performance 18 106-120

Shipley T F, Kellman P J, 1992b "Strength of visual interpolation depends on the ratio of physically specified to total edge length" Perception \& Psychophysics 52 97-106

Siegel S, Petry S, 1991 "Evidence for independent processing of subjective contour brightness and sharpness" Perception 20 233-241

Sigman E, Rock I, 1974 "Stroboscopic movement based on perceptual intelligence" Perception 3 $9-28$

Smith A T, Over R, 1975 "Tilt after-effects with subjective contours" Nature (London) 257 $581-582$

Smith A T, Over R, 1976 "Color-selective tilt aftereffects with subjective contours" Perception \& Psychophysics 20 305-308

Smith A T, Over R, 1977 "Orientation masking and the tilt illusion with subjective contours" Perception $6441-447$

Smith AT, Over R, 1979 "Motion aftereffect with subjective contours" Perception \& Psychophysics 25 95-98

Soriano M, Spillmann L, Bach M (in press) "The abutting grating illusion" Vision Research

Soubitez M C, 1982 "Perceptual development of the Ehrenstein illusion" Perception 1114

Spillmann L, 1975 "Perceptual modification of the Ehrenstein illusion", in Gestalttheorie in der modernen Psychologie. Festschrift für Wolfgang Metzger Eds S Ertl, L Kemmler, M Stadler (Darmstadt: Steinkopf) pp 210-218

Spillmann L, 1977 "Contrast and brightness illusions", in Spatial Contrast Eds H Spekreijse, L H van der Tweel (Amsterdam: North-Holland) pp 45-49

Spillmann L, 1994 "The Hermann grid illusion: A tool for studying human perceptive field organization" Perception 23 691-708

Spillmann L, Fuld K, Gerrits H J M, 1976 "Brightness contrast in the Ehrenstein illusion" Vision Research 16 713-719

Spillmann L, Fuld K, Neumeyer C, 1984 "Brightness matching, brightness cancellation, and increment threshold in the Ehrenstein illusion" Perception 13 513-520

Spillmann L, Redies C, 1981 "Random-dot motion displaces Ehrenstein illusion" Perception 10 $411-415$

Stadler M, Dieker J, 1969 "Margini quasi-percettivi e after-effects figurali" Rivista di Psicologia $6395-104$ 
Stadler M, Dieker J, 1972 "Untersuchungen zum Problem virtueller Konturen in der visuellen Wahrnehmung" Zeitschrift für Experimentelle und Angewandte Psychologie 19325 - 350

Tuijl H F J M van, 1975 "A new visual illusion: Neonlike color spreading and complementary color induction between subjective contours" Acta Psychologica 39 441-445

Tuijl H F J M van, Weert C M M de, 1979 "Sensory conditions for the occurrence of the neon spreading illusion" Perception 8 211-215

Tyler C W 1977 "Is the illusory triangle physical or imaginary?" Perception 6 603-604

Tynan P, Sekuler R, 1975 "Moving visual phantoms: A new contour completion effect" Science $188951-952$

Ullman S, 1976 "Filling-in the gaps: the shape of subjective contours and a model for their generation" Biological Cybernetics 25 1-6

Ullman S, 1984 "Visual routines" Cognition 18 97-159

Vallortigara G, 1987 "The hidden face of the Kanizsa triangle: Apparent movement of subjective figures in three-dimensional space" Perception 16 449-452

Varin D, 1971 "Fenomeni di contrasto e diffusione cromatica nell'organizzazione spaziale del campo percettivo" Rivista di Psicologia 65 101-128

Vogels R, Orban G A, 1987 "Illusory contour orientation discrimination" Vision Research 27 453-467

Wallach H, Slaughter V, 1988 "The role of memory in perceiving subjective contours" Perception \& Psychophysics 43 101-106

Ware C, 1980 "Coloured illusory triangles due to assimilation" Perception 9 103-107

Ware C, 1981 "Subjective contours independent of subjective brightness" Perception \& Psychophysics $29500-504$

Ware C, Kennedy J M, 1977 "Illusory line linking solid rods" Perception 6 601-602

Ware C, Kennedy J M, 1978 "Perception of subjective lines, surfaces and volumes in 3-dimensional constructions" Leonardo $11111-114$

Watanabe T, Cavanagh P, 1991 "Texture and motion spreading, the aperture problem, and transparency" Perception \& Psychophysics 50 459-464

Watanabe T, Cavanagh P, 1993 "Surface decomposition accompanying the perception of transparency" Spatial Vision 7 95-111

Watanabe T, Oyama T, 1988 "Are illusory contours a cause or a consequence of apparent differences in brightness and depth in the Kanizsa square?" Perception 17 513-521

Weerd P de, Vandenbussche E, Bruyn B de, Orban G A, 1990 "Illusory contour orientation discrimination in the cat" Behavioural Brain Research 39 1-17

Weert C M M de, Kruysbergen N A W H van, 1987 "Subjective contour strength and perceptual superimposition: Transparency as a special case", in The Perception of Illusory Contours Eds S Petry, G E Meyer(New York: Springer) pp 165-170

Weisstein N, Maguire W, 1978 "Computing the next step: Psychophysical measures of representation and interaction", in Computer Vision Systems Eds A R Hanson, E M Riseman (New York: Academic Press) pp 243-260

Weisstein N, Maguire W, Berbaum K, 1977 "A phantom-motion aftereffect" Science 198 955- 957

Wertheimer M, 1923 "Untersuchungen zur Lehre von der Gestalt, II" Psychologische Forschung 4 $301-350$

Whitmore C L G, Lawson R B, Kozora C E, 1976 "Subjective contours in stereoscopic space" Perception \& Psychophysics 19 211-213

Wildman K N, 1974 "Visual sensitivity at an edge" Vision Research 14 749-755

Zanforlin M, 1981 "Visual perception of complex forms in chicks" Italian Journal of Psychology $81-16$

Zucker S, Cavanagh P, 1985 "Subjective figures and texture perception" Spatial Vision 1 $131-139$

Zucker S W, Davis S, 1988 "Points and end-points: a size/spacing constraint for dot grouping" Perception 17 229-247 